\title{
Characterization of Polyoxometalate/Polymer photo-composites: a Toolbox for the Photodegradation of Organic Pollutants
}

Mariem Ghali $^{\mathrm{a}, \mathrm{b}, \mathrm{c}, \mathrm{d}}$, Chaima Brahmi ${ }^{\mathrm{a}, \mathrm{b}, \mathrm{c}, \mathrm{d}}$, Mahmoud Benltifa*c ${ }^{* \mathrm{c}}$ Cyril Vaulot $^{\mathrm{a}, \mathrm{b}}$, Aissam Airoudj $^{\mathrm{a}, \mathrm{b}}$, Philippe Fioux ${ }^{\mathrm{a}, \mathrm{b}}$, Frédéric Dumur ${ }^{\mathrm{e}}$, Corine Simonnet-Jégat ${ }^{\mathrm{f}}$, Fabrice MorletSavary $^{\mathrm{a}, \mathrm{b}}$, Salah Jellali ${ }^{\mathrm{g}}$, Latifa Bousselmi ${ }^{\mathrm{c}}$, Jacques Lalevée* a,b

${ }^{a}$ University of Haute-Alsace, CNRS, IS2M UMR 7361, F-68100 Mulhouse, France ${ }^{\mathrm{b}}$ University de Strasbourg, France

${ }^{c}$ Wastewaters and Environment Laboratory, Center for Water Research and Technologies CERTE, BP 273, Soliman 8020, Tunisia

${ }^{\mathrm{d}}$ University of Carthage, National Institute of Applied Sciences and Technology, Tunis 1080, Tunisia

e Aix Marseille Univ, CNRS, ICR, UMR7273, F-13397 Marseille (France)

${ }^{\mathrm{f}}$ Institut Lavoisier de Versailles, UMR CNRS 8180, Université Paris Saclay, Université de Versailles St-Quentin en Yvelines, 45 Avenue des Etats-Unis, 78035 Versailles cedex, France ${ }^{g}$ PEIE Research Chair for the Development of Industrial Estates and Free Zones, Center for Environmental Studies and Research, Sultan Qaboos University, Al-Khoud 123, Muscat, Oman

*Corresponding author: Jacques.lalevee@uha.fr and mahmoud_fsm@yahoo.fr

\begin{abstract}
:
Different inorganic/organic photo-composites based on Polyoxometalate (POM) nanoparticles have been developed for photocatalytic applications. Currently, polyoxometalate nanoparticles have been successfully in-situ embedded into an acrylate polymer network by photopolymerization upon mild visible light irradiation at $405 \mathrm{~nm}$. The proposed POM/polymer photocomposites have been characterized using complementary techniques for a better understanding of their photocatalytic activity. Interestingly, the obtained photocomposites exhibit high rigidity, excellent thermal stability, a non-negligible porosity and new functionalities such as light reactivity and redox properties. Moreover, developed composites showed efficient catalytic activity for the color removal of aqueous solutions of Erythrosine B and rose Bengal under Light Emitting Diodes LED@375 nm irradiation reaching 80\% and 90\% as a final discoloration rate respectively.
\end{abstract}




\section{Introduction}

Nowadays, nanocomposites materials are receiving a lot of attention to create new functional materials with specific properties across many fields. ${ }^{1,2}$ Actually, incorporation of metal nanoparticles into polymers can offer enhanced properties to the generated composites. ${ }^{3}$ Indeed, on one hand, inorganic inclusions reinforce mechanical strength and enrich the functionalities of polymer materials and on the other hand, the polymer can be used to immobilize nano-building blocks and ensures high processability and reuse opportunities. ${ }^{4}$ This operation yields versatile functional composites with a wide range of potential applications such as conductivity, isolation, luminescence and light absorption. ${ }^{3,5}$

Polyoxometalates (POMs) are a vast class of green and stable early transition metal oxide clusters with a variety of molecular structures and properties. ${ }^{6}$ Indeed, POMs exhibit simple to highly complex topologies. Metal ions are ranging from 6 to 368 units, can organize different subunits with monodisperse size ranging from Angstroms up to $10 \mathrm{~nm} .^{7}$ Therefore, POMs present promising building blocks for nanocomposite materials. ${ }^{1,2}$ Different techniques were used for the fabrication of inorganic-organic POM nanocomposites such as the chemisorption on carbon surfaces, the layer by layer self-assembly and immobilization in a polymer matrix using chemical and electrochemical routes. ${ }^{14}$

Besides their relatively low cost, POMs have interesting properties including Bronsted acidity, redox properties, oxidative and thermal stability and strong UV light absorption. ${ }^{8}$

Currently, POMs can undergo fast and reversible multi-electron transfer without decomposition ${ }^{9}$ which is the key step for their redox properties and regeneration cycle (by reoxidation). ${ }^{10}$ Moreover, POMs in suspension have been used extensively in catalysis and photocatalysis for water splitting ${ }^{11}$, hydrolysis of esters ${ }^{12}$, oxidation of organic compounds such as hydrocarbons ${ }^{13}$ and aqueous organic contaminant removal including dyes ${ }^{13-15}$ and pesticides $^{16,17,18}$, etc. Additional functional properties of POMs have also been reported for different applications such as magnetism ${ }^{13}$, ionic conductivity $^{19}$ and photo or electrochromism. $^{20}$

However, the difficulty in exploiting POMs as functional materials in practical applications stems from their high solubility in aqueous solutions or organic solvents because of their strong Bronsted acid property i.e. $\mathrm{H}_{3} \mathrm{~W}_{12} \mathrm{O}_{40}\left(\mathrm{pKa}_{1}=1.5 ; \mathrm{pKa}_{2}=3\right)$ and $\mathrm{H}_{3} \mathrm{PMo}_{12} \mathrm{O}_{40}$ $(\mathrm{pKa}=1.5)^{21}$, which prevents their easy recovery and reuse. To overcome these problems, researchers have reported different methods for more effective and cheaper photocatalytic applications, such as POMs impregnation on semiconductors ${ }^{22,23}$, combination with counter 
ions to give insoluble salts ${ }^{24}$, entrapping onto active carbon ${ }^{25}$ and nanocomposites development. ${ }^{26,27}$ Through the development of nanocomposite materials, the POMs functionalities can be exploited. ${ }^{28-30}$ Actually, the synthesis of functional nanocomposites requires the development of an efficient strategy adapting POM particles immobilization within a polymer that should be tailored to meet up the needs of the intended application.

In this context, our challenge consists of developing an easy and soft methodology of hybrid inorganic/organic POM/polymer composite synthesis for photocatalytic organic pollutants removal without inhibiting the catalytic properties of POMs nanoparticles.

Compared to the most popular inorganic photocatalyst (Titanium dioxide - $\mathrm{TiO}_{2}$ ) that received much attention in the field of photocatalysis ${ }^{31-40}$, there are only few reported studies dealing with the characterization of $\mathrm{POM} /$ polymer composites for heterogeneous photocatalysis. ${ }^{41-45}$

Therefore, the present work originally focuses on a) polyoxometalate/polymer (POM/polymer) photo-composites preparation, by photopolymerization thanks to its process advantages: solvent-free reactions achieved at ambient temperature and high-speed process ${ }^{46}$ using safe and cheap LED irradiation conditions, b) evaluation of the photocatalytic properties of composites on erythrosine B and rose Bengal discoloration upon LED exposure and c) full $\mathrm{POM}$ /polymer photo-composites characterization: stability, surface structure, porosity, optical properties and regeneration that were realized with a wide range of analytical techniques using Scanning Electron Microscopy (SEM), Transmission Electron Microscopy (TEM), Atomic Force Microscopy (AFM), Energy-dispersive X-ray analyses (EDX), BET specific surface, Dynamic Mechanical Analysis (DMA), Thermogravimetric Analysis (TGA) and Electron Spin Resonance (ESR). To the best of our knowledge, this is the first detailed characterization of the inorganic/organic POM/polymer composites (from the microscopic to the macroscopic scales).

\section{Experimental section}

\subsection{Chemical compounds}

$\mathrm{H}_{3} \mathrm{PMo}_{12} \mathrm{O}_{40}{ }^{47}, \quad \mathrm{SiMo}_{12} \mathrm{O}_{40}\left(\mathrm{IPh}_{2}\right)_{4}, \mathrm{~W}_{10} \mathrm{O}_{32}\left(\mathrm{IPh}_{2}\right)_{4}, \mathrm{~W}_{10} \mathrm{O}_{32}(\mathrm{TH})_{4}{ }^{48}$ were synthesized according to reported procedures (See Figure 1). Trimethylolpropane triacrylate (TMPTA from Allnex) was selected as monomer for composite synthesis. Bis(4-tert-butylphenyl)iodonium hexafluorophosphate (Iod also noted Speedcure 938), Phenyl bis(2,4,6-trimethylbenzoyl) phosphine oxide (BAPO or Speedcure BPO) were obtained from Lambson Ltd (UK), Erythrosine B and rose Bengal from Sigma Aldrich. 


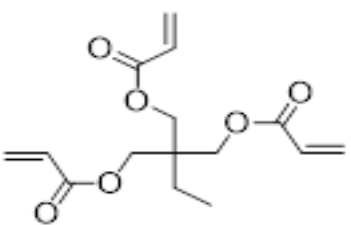

TMPTA<smiles>CC(C)(C)c1ccc([I-]c2ccc(C(C)(C)C)cc2)cc1</smiles>

Iodonium salt (Iod)

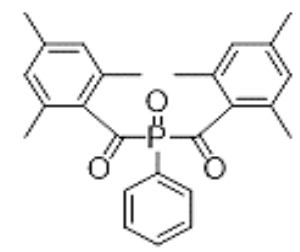

BAPO

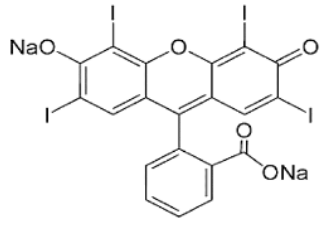

Erythrosine B

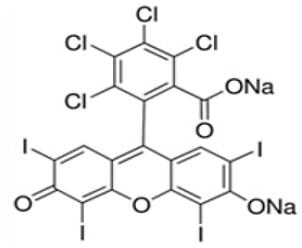

Rose Bengal

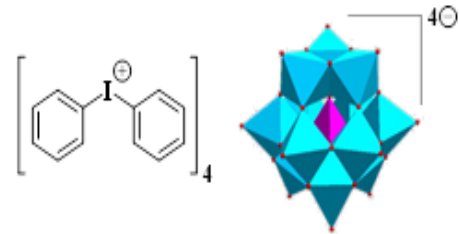

$\mathrm{SiMo}_{12}\left(\mathrm{IPh}_{2}\right)_{4}$

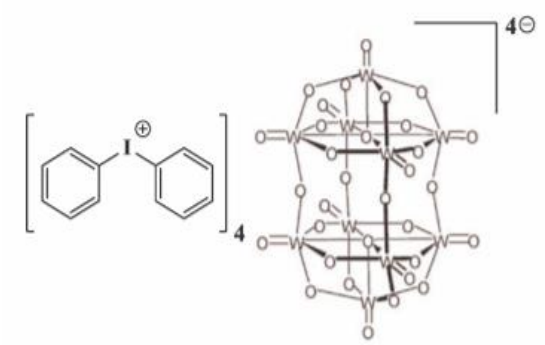

$\mathrm{W}_{10} \mathrm{O}_{32}\left(\mathrm{IPh}_{2}\right)_{4}$

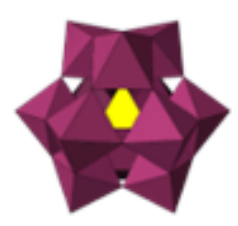

$\mathrm{H}_{3} \mathrm{PMo}_{12} \mathrm{O}_{40}$
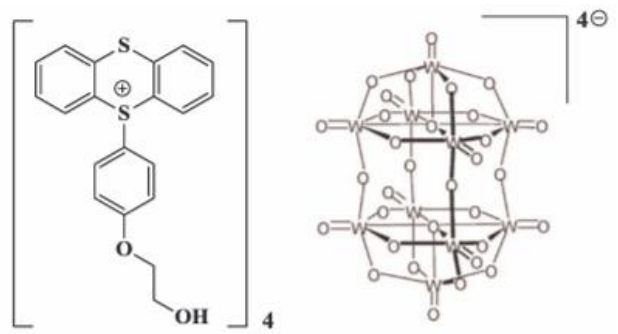

$\mathrm{W}_{10} \mathrm{O}_{32}(\mathrm{TH})_{4}$

Figure 1. Chemical structures of the main compounds used in this work

\subsection{Photopolymerization experiments}

In this work, polymolybdates and polytungstates were in-situ embedded in acrylate monomer (TMPTA). Free radical polymerization of acrylates functions occurred using the following methods. The photopolymerization experiments were carried out under air. For thick composites, the photosensitive resins $\left[\mathrm{BAPO} / \mathrm{Iod} / \mathrm{POM} \quad(0.2 \% / 1 \% / 1 \% \text { w/w/w) }]^{49}\right.$ were deposited in a mold to define the final shape of polymer or composite, $1.3 \mathrm{~mm}$ ). For thin composites (formulations were sandwiched between two propylene films, $25 \mu \mathrm{m}$ ). The evolution of the double bond content of TMPTA during the polymerization reaction was followed by real-time Fourier transform infrared spectroscopy at $4730 \mathrm{~cm}^{-1}$ and $1630 \mathrm{~cm}^{-1}$ for thick and thin samples respectively. Light Emitting Diodes LED@405 nm, $\mathrm{I}_{0}=100 \mathrm{~mW} . \mathrm{cm}^{-2}$ was used as the irradiation source. ${ }^{50}$

\subsection{Photocatalytic activity}


Photocatalytic activity of $1 \% \mathrm{H}_{3} \mathrm{PMo}_{12} \mathrm{O}_{40} /$ polymer and $1 \% \mathrm{~W}_{10} \mathrm{O}_{32}\left(\mathrm{IPh}_{2}\right)_{4} /$ polymer composites was evaluated by measuring over time the evolution of the absorbance of aqueous solutions of erythrosine $(10 \mathrm{mg} / \mathrm{L})$ at $526 \mathrm{~nm}$ and rose Bengal $(10 \mathrm{mg} / \mathrm{L})$ at $550 \mathrm{~nm}$ upon Light Emitting Diodes LED@375 nm, $\mathrm{I}_{0}=70 \mathrm{~mW} . \mathrm{cm}^{-2}$ exposure. A JASCO V730 spectrometer was used for the UV-visible absorption measurements.

The dye consumption at different irradiation time was calculated by the following formula (eq.1):

$\left(1-\frac{A b s t}{A b s t=0}\right) \times 100$

Where $A b s t=0$ and $A b s t$ are the measured dyes absorbances before and after a given time ' $\mathrm{t}$ ' of irradiation.

\subsection{Composites stability}

\subsubsection{Stability in water}

Swelling experiments were realized after impregnation of composites in water for $24 \mathrm{~h}$, The swelling ratio is calculated using the following formula (eq.2):

Swelling $=\left(\frac{\mathrm{Ws}}{\mathrm{Wd}}-1\right) \times 100$

Where $\mathrm{W}_{\mathrm{d}}$ is the initial weight of polymer or composite and $\mathrm{W}_{\mathrm{s}}$ is the weight of swollen polymer or composite.

Also, the dry extracts of the composites were determined after the swelling experiments by drying them in a vacuum at $50^{\circ} \mathrm{C}$ for $1 \mathrm{~h}$. The dry extract is calculated using the following formula (eq.3):

Dry extract $=\frac{\mathrm{Wsd}}{\mathrm{Wd}} \times 100$

Where $\mathrm{W}_{\mathrm{sd}}=$ Weight of dried polymer or composite after swelling.

\subsubsection{Thermal stability}

The Thermogravimetric Analysis (TGA) was realized using a METTLER TOLEDO TGA/DSC 3+ equipment. The experiments were carried out at temperatures ranging from $30^{\circ} \mathrm{C}$ to $800{ }^{\circ} \mathrm{C}$ and were accessed at a heating rate of $10 \mathrm{~K} / \mathrm{min}$ under a dry air flow of $100 \mathrm{~mL} / \mathrm{min}$.

\subsection{Composites characterization}

\subsubsection{Morphological characterization}


For morphological characterization, JSM-7900F Scanning Electron Microscopy (SEM) from JEOL was used in this study. It is equipped with an annular detector from DEBEN for transmission images.

\subsubsection{Chemical analysis}

Energy-dispersive X-ray analyses were realized using the system QUANTAX double detector from Bruker.

\subsubsection{Surface properties and rigidity of composites}

Surface properties and rigidity of the different composites were examined using AFM technique. AFM measurements were performed using a Bruker Multimode IV, with a Nanoscope V controller and an E "vertical” scanner (Bruker), by the Peak Force Quantitative Nanomechanical Mapping (PF-QNM, Bruker) method. PF-QNM is a contact AFM mode, based on the force-volume method. ${ }^{51}$ A calibration procedure was first followed. All quantitative measurements were carried out with NCLR cantilever (Nano World) with a spring constant of $48 \mathrm{~N} / \mathrm{m}$ and a resonance frequency of $190 \mathrm{kHz}$, a width of $38 \mu \mathrm{m}$ and a length of $225 \mu \mathrm{m}$. Thanks to the Sader method ${ }^{52}$, the actual spring constant was determined and found to be around $27 \mathrm{~N} / \mathrm{m}$. Then, the deflection sensitivity (around $32 \mathrm{~nm} / \mathrm{V}$ ) was measured on a sapphire surface. The Tip radius was calibrated against a polystyrene standard provided by Bruker. The measured value of the tip radius was $10 \mathrm{~nm}$. The Poisson's ratio was assumed to be equal to 0.3 . To get relevant results, the cantilever and the tip geometry are taking into account in the PF-QNM measurements. For all experiments, an area of $5 \mu \mathrm{m} \times 5 \mu \mathrm{m}(256 \times 256$ pixels at $0.6 \mathrm{~Hz}$ ) was taken at three different areas on the sample surface.

\subsubsection{Textural properties and porosity}

The textural characteristics of the different samples were determined from nitrogen adsorption/desorption at $77.35 \mathrm{~K}$ using micromeritics ASAP 2420 instrument. BET specific surface area and average pore diameter (Gurlich law) were calculated by using the standard Brunauer, Emmett, and Teller (BET) method based on adsorption data.

The samples were degassed at $25^{\circ} \mathrm{C}$ for 60 hours on degassing port and weighted. Then, the samples were degassed once again at $25^{\circ} \mathrm{C}$ for 4 hours on the analysis port to extract the trapped nitrogen. The analyses were realized with a reactor of the free volume to optimize the measurement and the free volumes were determined after analysis to avoid the pollution of the samples.

\subsubsection{Mechanical properties in bulk}

Dynamic storage modulus G' and dynamic loss modulus G', of different synthesized composites were evaluated to have an idea about their mechanical properties in bulk. The 
Dynamic Mechanical Analysis (DMA) was measured using a DMA METTLER TOLEDO DMA861e equipment.

\subsubsection{Optical properties}

Due to the opaque nature of the composites, spectroscopy measurements were performed using the UV-Visible spectrophotometer (Jasco V-750) equipped with an integrating sphere.

\subsubsection{Electron Spin Resonance (ESR) experiments}

ESR experiments were realized to investigate the reactivity of POM/polymer composites under light irradiation using EMX PLUS (Bruker) spectrometer. Different composites were irradiated at room temperature upon LED@405 nm, $\mathrm{I}_{0}=120 \mathrm{~mW} \cdot \mathrm{cm}^{-2}$. The EPR spectra simulations were realized with the WINSIM software.

\section{Results and discussions}

\subsection{Synthesis of POM/polymer composites by photopolymerization}

The photopolymerization process was used to synthesize the different POM/Polymer composites (see section 2.2) by transforming the liquid filled formulation containing TMPTA as the monomer and POM as the fillers. The photoinitiating system i.e. BAPO/Iod $(0.2 \% / 1 \%$ $(\mathrm{w} / \mathrm{w}))$ is very reactive upon LED@405 nm irradiation. The obtained photopolymerization profiles for the free radical polymerization (FRP) of TMPTA are reported in Figure 2.

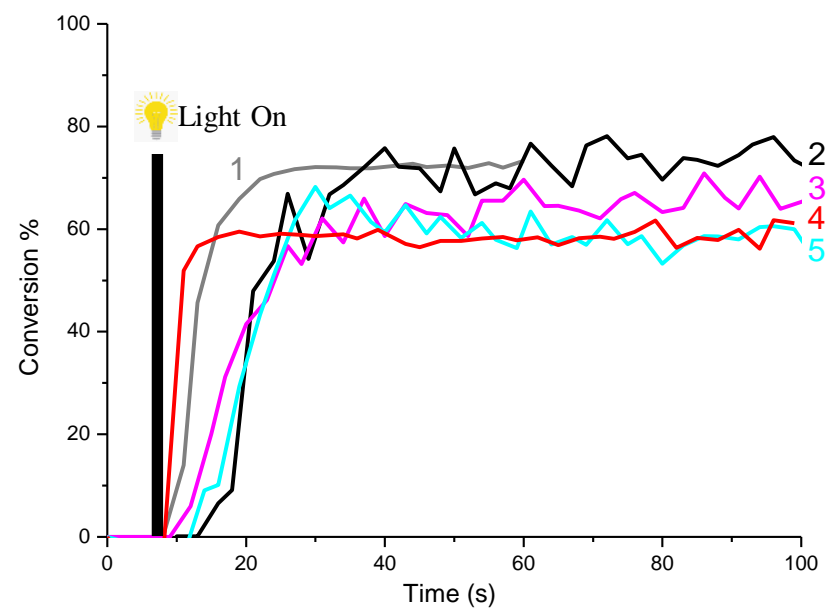

Figure 2. Photopolymerization profiles of TMPTA (double bond conversion vs irradiation time) (thickness $=1.3 \mathrm{~mm}$ ) under air upon the exposure to LED@405 nm in the presence of different systems (1) BAPO/Iod $(0.2 \% / 1 \%(\mathrm{w} / \mathrm{w}))$ (unfilled sample), $\mathrm{BAPO} / \mathrm{Iod} / \mathbf{W}_{\mathbf{1 0}} \mathbf{O}_{\mathbf{3 2}}\left(\mathbf{I P h}_{2}\right)_{4} \quad(0.2 \% / 1 \% / 1 \% \quad \mathrm{w} / \mathrm{w} / \mathrm{w}), \quad(3) \quad \mathrm{BAPO} / \mathrm{Iod} / \mathbf{S i M o 1 2}_{\mathbf{4 0}}(\mathbf{I P h})_{4}$ 
$(0.2 \% / 1 \% / 1 \% \quad \mathrm{w} / \mathrm{w} / \mathrm{w}), \quad(4) \quad \mathrm{BAPO} / \mathrm{Iod} / \mathrm{W}_{10} \mathbf{O}_{32}(\mathbf{T H})_{4} \quad(0.2 \% / 1 \% / 1 \% \quad \mathrm{w} / \mathrm{w} / \mathrm{w})$,

$\mathrm{BAPO} / \mathrm{Iod} / \mathrm{H}_{3} \mathbf{P M O} \mathbf{1 2}_{2} \mathbf{O}_{40}(0.2 \% / 1 \% / 1 \% \mathrm{w} / \mathrm{w} / \mathrm{w})$. The irradiation starts for $\mathrm{t}=7 \mathrm{~s}$.

In the absence of polyoxometalates, the final conversion of acrylate functions reached $72 \%$ at $\mathrm{t}=30 \mathrm{~s}$ of a LED@ $405 \mathrm{~nm}$ irradiation (Figure 2; curve 1). In presence of POM as fillers (Figure 2, curves 2-5 vs. curve 1), it is obvious that the polymerization performance slightly decreases (both for the final acrylate function conversions ( $\mathrm{FCs}$ ) and the polymerization rates) compared to the unfilled sample e.g. for the system BAPO/Iod/SiMo12 $\mathbf{O}_{40}\left(\mathrm{IPh}_{2}\right)_{4} \mathrm{FC}=63 \%$ after $40 \mathrm{~s}$ compared to $>70 \%$ for the unfilled sample. These results could be explained by the light scattering originating from the POMs nanoparticles, inhibiting the light penetration into the formulation. Light irradiation at $405 \mathrm{~nm}$ was specifically selected to prevent the direct excitation of $\mathrm{POMs}^{12}$ during the polymerization process since they do not exhibit high light absorption properties at $405 \mathrm{~nm}$ (see Figure 3).

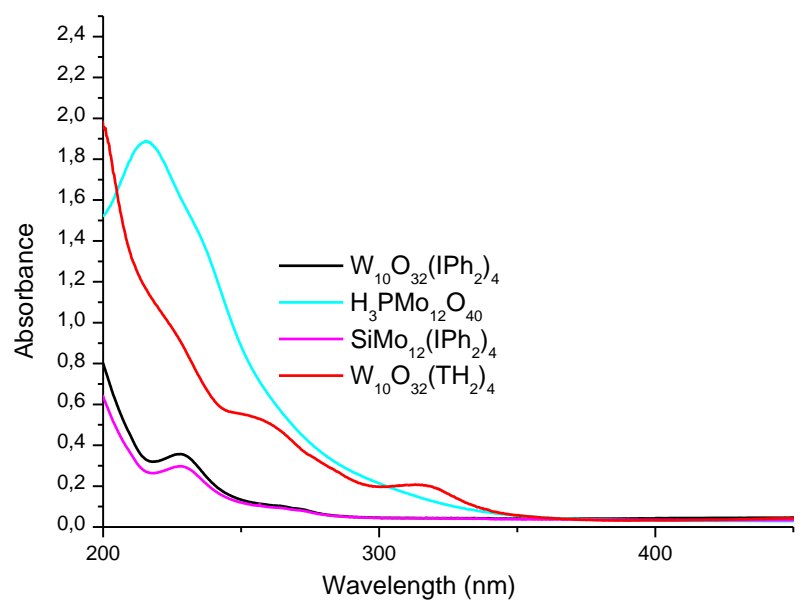

Figure 3. UV-Vis absorption spectra of different polyoxometalates in water: $\mathrm{W}_{10} \mathrm{O}_{32}\left(\mathrm{IPh}_{2}\right)_{4}$ $(250 \mathrm{mg} / \mathrm{L}), \mathrm{H}_{3} \mathrm{PMo}_{12} \mathrm{O}_{40}(65 \mathrm{mg} / \mathrm{L}), \mathrm{SiMo}_{12} \mathrm{O}_{40}\left(\mathrm{IPh}_{2}\right)_{4}(150 \mathrm{mg} / \mathrm{L}), \mathrm{W}_{10} \mathrm{O}_{32}\left(\mathrm{IPh}_{2}\right)_{4}(370 \mathrm{mg} / \mathrm{L})$.

\subsection{Effect of POMs concentration and composite thickness}

The influence of the $\mathrm{H}_{3} \mathrm{PMo}_{12} \mathrm{O}_{40}$ content on the polymerization profiles was examined and the results are shown in Figure 4. 


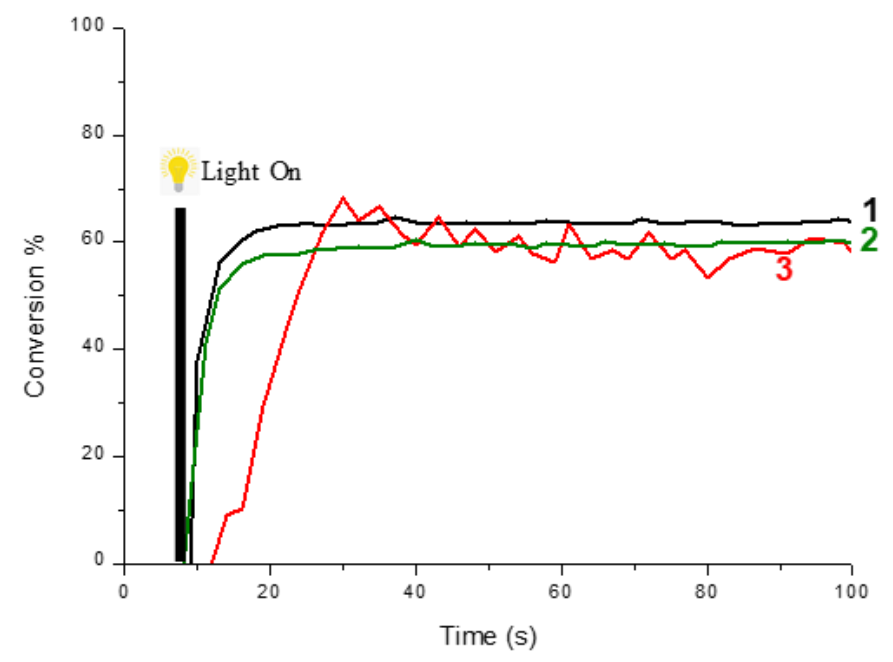

Figure 4. Photopolymerization profiles of acrylate functions (double bond conversion vs irradiation time) under air upon exposure to a LED@405 nm in the presence of (1) BAPO/Iod $/ \mathrm{H}_{3} \mathrm{PMo}_{12} \mathrm{O}_{40}(0.2 \% / 1 \% / 1 \%(\mathrm{w} / \mathrm{w} / \mathrm{w}))$ for thin composite $(25 \mu \mathrm{m})$ synthesis, (2) $\mathrm{BAPO} / \mathrm{Iod} / \mathrm{H}_{3} \mathrm{PMo}_{12} \mathrm{O}_{40}(0.6 \% / 3 \% / 3 \%(\mathrm{w} / \mathrm{w} / \mathrm{w}))$ for thin composite $(25 \mu \mathrm{m})$ synthesis and (3) $\mathrm{BAPO} / \mathrm{Iod} / \mathrm{H}_{3} \mathrm{PMo}_{12} \mathrm{O}_{40}(0.2 \% / 1 \% / 1 \%(\mathrm{w} / \mathrm{w} / \mathrm{w}))$ for thick composite $(1.3 \mathrm{~mm})$ synthesis. The irradiation starts for $\mathrm{t}=7 \mathrm{~s}$.

Final acrylate function conversion (FC) decreases when increasing the concentration of $\mathrm{H}_{3} \mathrm{PMo}_{12} \mathrm{O}_{40}$ (Figure 4 curves 2 vs 1 ) i.e. $\mathrm{FC}=65 \%$ at $20 \mathrm{~s}$ for $\mathrm{H}_{3} \mathrm{PMo}_{12} \mathrm{O}_{40} 1 \%$ in weight vs. $\mathrm{FC}=60 \%$ at $20 \mathrm{~s}$ for $\mathrm{H}_{3} \mathrm{PMo}_{12} \mathrm{O}_{40} 3 \%$ in weight despite a higher photoinitiator content in curve 2 to compensate the higher light scattering issued from the fillers. This result is explained by the more limited light penetration into the photocurable formulation caused by the increase of the $\mathrm{H}_{3} \mathrm{PMo}_{12} \mathrm{O}_{40}$ content.

Obviously, the thickness of the synthesized composite affects the polymerization profile. Indeed, for similar conditions, thick composites $(1.3 \mathrm{~mm})$ are more difficult to polymerize than the thinner ones (see Figure 4 curve 3 vs. curve 1). Thicker samples are characterized by lower polymerization rates as well as lower final conversions compared to the thinner ones again in agreement with a better light penetration in thinner composites.

\subsection{Photocatalytic activity of composite}

Very few POM/polymer composites were proposed for photocatalytic organic pollutants removal (e.g. our reported work on effective eosin-Y photodegradation in organic solvent ${ }^{49}$ ). Therefore, it is still important to evaluate the composite's photocatalytic activity for other dyes removal. This property was investigated for both $\mathrm{H}_{3} \mathrm{PMo}_{12} \mathrm{O}_{40} /$ polymer and 
$\mathrm{W}_{10} \mathrm{O}_{32}\left(\mathrm{IPh}_{2}\right)_{4} /$ polymer composites for the photodegradation of erythrosine $\mathrm{B}$ and rose Bengal in aqueous solution using LED@375 nm irradiation. Obtained results are reported in Figure 5.

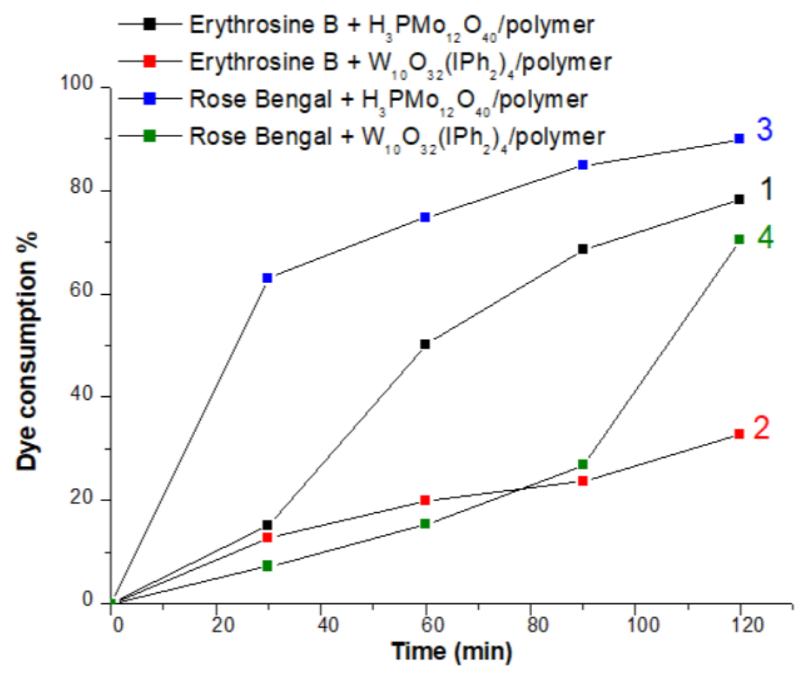

Figure 5. Erythrosine B $(10 \mathrm{mg} / \mathrm{L})$ consumption under LED@375 nm irradiation in the presence of (1) $1 \% \mathrm{H}_{3} \mathrm{PMo}_{12} \mathrm{O}_{40}$ /polymer composite and (2) $1 \% \mathrm{~W}_{10} \mathrm{O}_{32}\left(\mathrm{IPh}_{2}\right)_{4} /$ polymer composite. Rose Bengal $(10 \mathrm{mg} / \mathrm{L})$ consumption under LED@375 nm irradiation in the presence of (3) $1 \% \mathrm{H}_{3} \mathrm{PMo}_{12} \mathrm{O}_{40}$ /polymer composite and (4) $1 \% \mathrm{~W}_{10} \mathrm{O}_{32}\left(\mathrm{IPh}_{2}\right)_{4} /$ polymer composite.

The color removal of both erythrosine and rose Bengal demonstrates the efficient photocatalytic activity of the synthesized composites under LED@375 nm irradiation.

Indeed, the conversion of erythrosine $\mathrm{B}$ in the presence of the composite $1 \%$ $\mathrm{H}_{3} \mathrm{PMo}_{12} \mathrm{O}_{40} /$ polymer (Figure 5 curve (1)) reached almost $80 \%$ after only $2 \mathrm{~h}$ of light exposure. However, in the presence of $1 \% \mathrm{~W}_{10} \mathrm{O}_{32}\left(\mathrm{IPh}_{2}\right)_{4} /$ polymer the erythrosine $\mathrm{B}$ conversion is only about 30\% (Figure 5 curve (2)). In the case of Rose Bengal, a high final removal rate was obtained reaching $90 \%$ after $2 \mathrm{~h}$ of irradiation in the presence of $1 \% \mathrm{H}_{3} \mathrm{PMo}_{12} \mathrm{O}_{40} /$ polymer (Figure 5 curve (3)). When using the $1 \% \mathrm{~W}_{10} \mathrm{O}_{32}\left(\mathrm{IPh}_{2}\right)_{4} /$ polymer composite, Rose Bengal final discoloration rate is about $70 \%$ after $2 \mathrm{~h}$ of light exposure (Figure 5 curve (4)).

Thus, these results demonstrate the photocatalytic activity of the developed POM/polymer composites for organic dyes removal from aqueous solution using soft near UV irradiation by LED@375 nm. Furthermore, we demonstrated in previous work the efficiency of the photocatalytic ability of POM/polymer composites for Eosin-Y total removal under LED@375 nm irradiation reaching 98\% as final conversion . ${ }^{49}$ 
However, there are very few studies dealing with the characterization of inorganic/organic POM/polymer composites for photocatalytic applications. In fact, Feng and collaborators ${ }^{42}$ realized polymer films of POMs/polyvinyl alcohol for the photodegradation of azo dyes: such as methyl orange, Congo red and Ponceau 2R reaching 99.6\%, 47.6\% and 72.4\% as maximal degradation conversion respectively. Where the SEM characterizations indicated that POMs and polyvinyl alcohol were intact after synthesis by impregnation. On his side, Yanglijun ${ }^{53}$ developed a multilayer film of $\left(\mathrm{PW}_{12} \mathrm{O}_{40}{ }^{3-}\right.$ Azure A) composite via a layer by layer self-assembly method for the photodegradation of methyl orange under UV and visible light irradiation for 150 min using a xenon lamp and solar irradiation reaching $99.6 \%$ as maximal degradation conversion. The examination of the resulting composites demonstrated that $\mathrm{PW}_{12} \mathrm{O}_{40}{ }^{3-}$ was intact after the self-assembly process and the film surface was smooth and uniform. In another work, Yanglijun ${ }^{43}$ focused on the synthesis of POM-Thionine composites by a precipitation method for the photocatalytic degradation and mineralization of rhodamine B after $60 \mathrm{~min}$ of visible light irradiation at $420 \mathrm{~nm}$ using a xenon lamp with a cutoff filter to eliminate the UV light. Here again, structural characterizations showed a relatively large surface area: a BET surface of $20.26 \mathrm{~m}^{2} / \mathrm{g}$ and a Langmuir surface of $31.59 \mathrm{~m}^{2} / \mathrm{g}$ were respectively determined. ${ }^{43}$

To the best of our knowledge, the development of hybrid POM/polymer composites by photopolymerization technique for the photocatalytic organic pollutant removal was only reported by us in a recent paper. Therefore, an important novelty of this paper is associated with the investigation and characterization of POM/polymer composites (stability, surface structure, porosity, mechanical properties, reactivity under light irradiation ...).

\subsection{Stability of composites}

\subsubsection{Stability in water}

To further estimates the stability in water, swelling experiments for the different composites were carried out in the water. Indeed, water is the most interesting solvent in photocatalysis for organic pollutants removal (see Table 1).

Table 1. Acrylates Final Conversion (FC \%), Swelling degree (\%) (in water) and dry extract degree $(\%)$ of different studied POM/polymer composites. 


\section{FC (\%) $\quad$ Swelling (\%) Dry extract (\%)}

\begin{tabular}{cccc}
\hline Polymer & 72 & 10 & 1 \\
\hline $\mathbf{1 \%}$ & 65 & 10 & 90 \\
H3PMo12 & & & \\
\hline $\mathbf{3 \%}$ \%olymer & & 0 & 90
\end{tabular}

$\mathrm{H}_{3} \mathrm{PMo}_{12} \mathrm{O}_{40} /$ polymer

\begin{tabular}{cccc}
\hline $\mathbf{1 \%}$ & 80 & 0 & 100 \\
$\mathbf{W}_{\mathbf{1 0}} \mathbf{O}_{\mathbf{3 2}}(\mathbf{I P h})_{4} /$ polymer & & & \\
\hline $\mathbf{3 \%}$ & 85 & 0 & 100 \\
$\mathbf{W}_{\mathbf{1 0}} \mathbf{O}_{\mathbf{3 2}}(\mathbf{I P h})_{4} /$ polymer & & &
\end{tabular}

According to the obtained swelling degree of the neat polymer and the $1 \%$ $\mathrm{H}_{3} \mathrm{PMO}_{12} \mathrm{O}_{40}$ /polymer composite (Table 1), a very low swelling degree about $10 \%$ is observed. This could be ascribed principally to the presence of porosity in their structure (see below). However, no swelling is observed for the other composites (Table 1) indicating a highly crosslinked acrylate network even though the presence of POMs nanoparticles. Indeed, the lower the swelling ratio is, the higher is the crosslinking density between monomers. This result is in good agreement with the obtained high final conversions of acrylates during the photopolymerization process for composite synthesis (see Figure 2). Remarkably, obtained dry extract degree (Table 1) indicate a low probability of monomer loss after the polymerization process. These results show the good stability of the POM/polymer composites in water.

\subsubsection{Thermal stability}

The thermal stability of the POMs/polymer composites was studied using Thermogravimetric Analysis TGA experiments to estimate their respective decomposition temperatures and mass loss at different temperatures. A comparison of filled vs. unfilled samples was also valuable.

Table 2. Decomposition temperatures and mass loss at the decomposition temperature for the developed unfilled sample (polymer) and the different composites (filled samples). 


\begin{tabular}{|c|c|c|}
\hline Sample & $\begin{array}{c}\text { Decomposition } \\
\text { temperature } \\
\left({ }^{\circ} \mathrm{C}\right)\end{array}$ & $\begin{array}{l}\text { The mass loss } \\
\text { at the } \\
\text { decomposition } \\
\text { temperature } \\
(\%)\end{array}$ \\
\hline Polymer & 475 & 30 \\
\hline $1 \% \mathrm{H}_{3} \mathrm{PMo12}_{4} \mathrm{O}_{40} /$ polymer & 465 & 21 \\
\hline $3 \% \mathrm{H}_{3} \mathrm{PMo}_{12} \mathrm{O}_{40} /$ polymer & 460 & 22 \\
\hline $1 \% \mathrm{~W}_{10} \mathrm{O}_{32}\left(\mathrm{IPh}_{2}\right)_{4} /$ polymer & 465 & 19 \\
\hline $3 \% \mathrm{~W}_{10} \mathrm{O}_{32}\left(\mathrm{IPh}_{2}\right)_{4} /$ polymer & 470 & 18 \\
\hline
\end{tabular}

TGA analyses revealed a high and stable degradation temperature for the different composites (Table 2) i.e. the degradation temperature remains very similar to that of the neat polymer (about $475^{\circ} \mathrm{C}$ ) suggesting that the POMs incorporation does not change this bulk property. Besides, the mass loss is less important in the case of composites compared to the neat polymer $(30 \%)$ due to the presence of POMs nanoparticles in the polymeric matrix. Therefore, the incorporation of POMs nanoparticles enhances the thermal stability of the polymer which promotes the potential application of these composites in the photocatalytic field.

\subsection{POM/Polymer composite characterization}

\subsubsection{Morphological and chemical characterization}

Morphology of the developed composites was examined using Transmission Electron Microscopy TEM and Scanning Electron Microscopy SEM. TEM images of only the polymer used to host for the POMs nanoparticles showed a homogeneous surface morphology (Figure 6 (h)). Two different composites based on $\mathrm{H}_{3} \mathrm{PMo}_{12} \mathrm{O}_{40}$ or $\mathrm{W}_{10} \mathrm{O}_{32}\left(\mathrm{IPh}_{2}\right)_{4}$ were studied. 

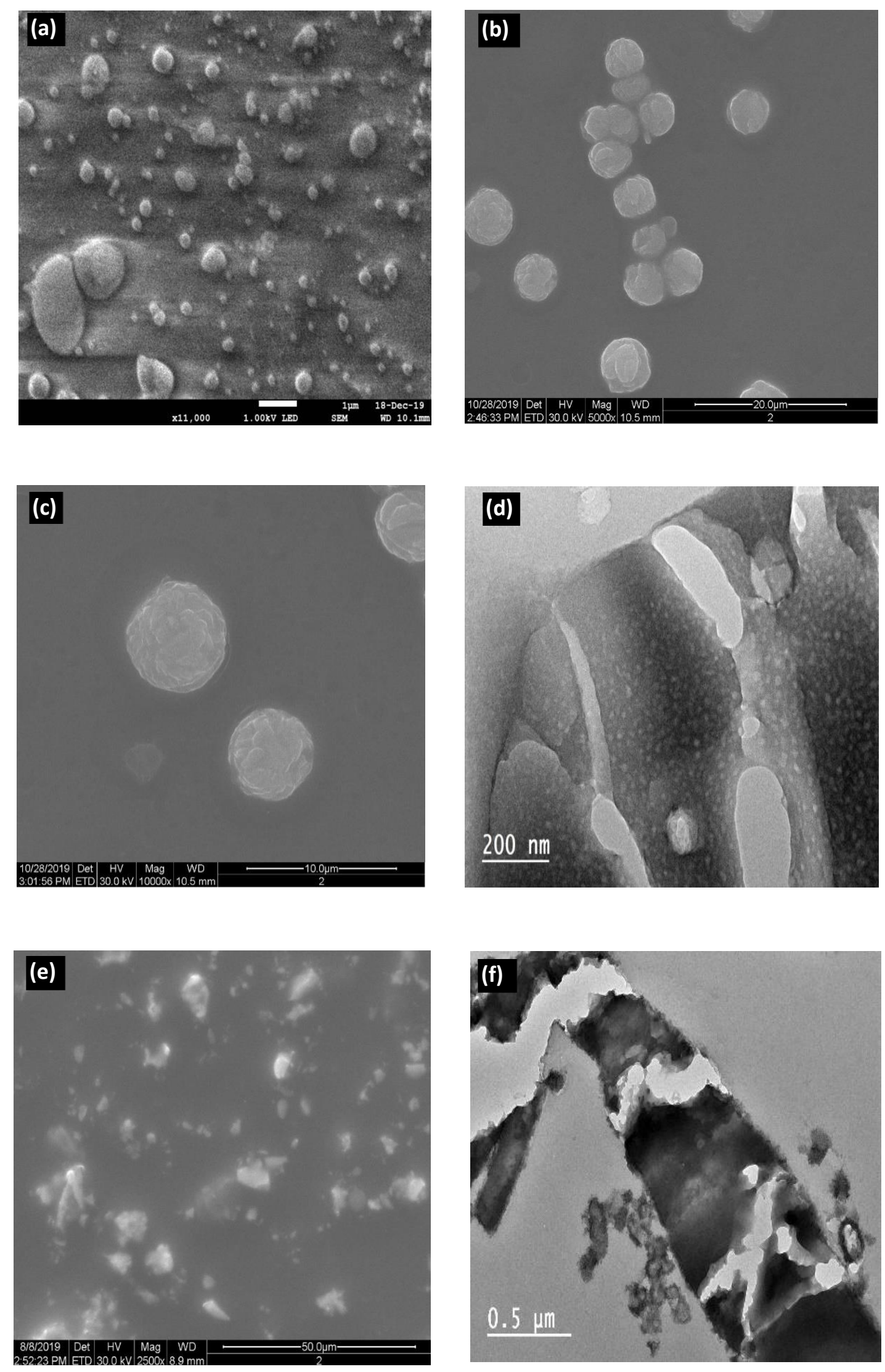

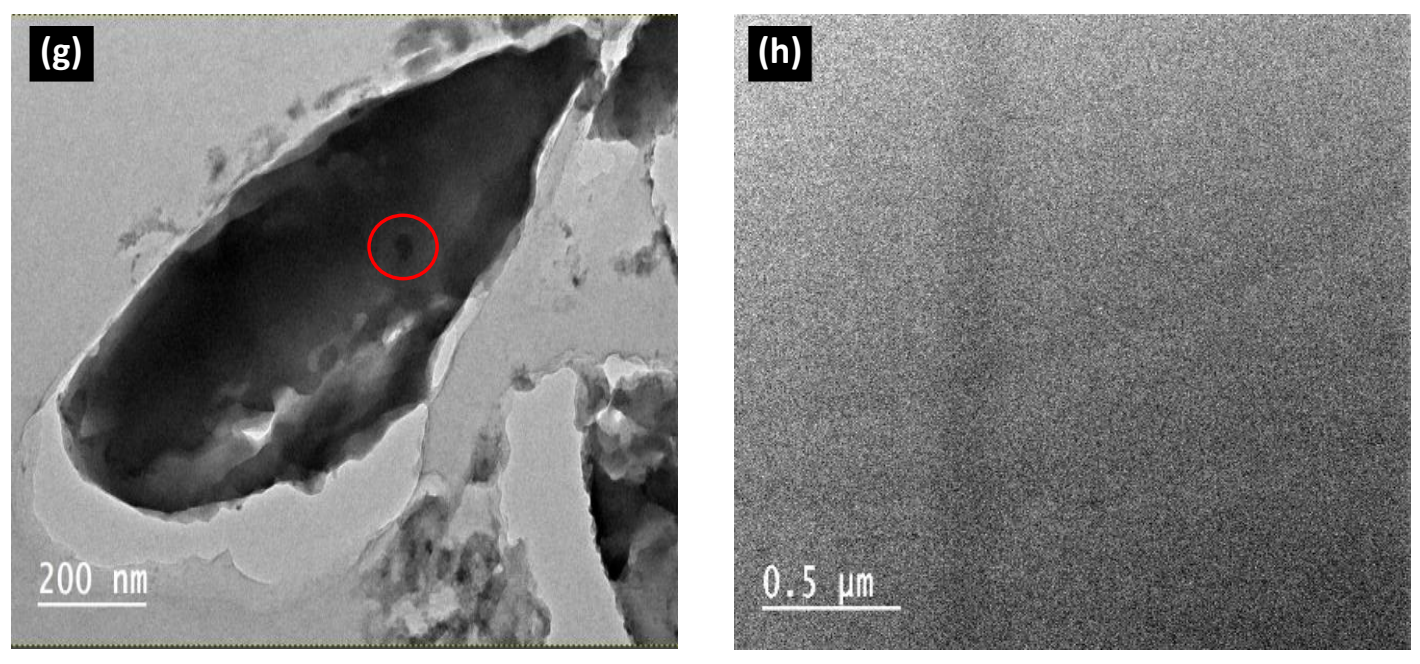

Figure 6. (a, b, c) SEM images of $\mathrm{H}_{3} \mathrm{PMo}_{12} \mathrm{O}_{40}$ /polymer composites at different scales; (d) TEM image of $\mathrm{H}_{3} \mathrm{PMo}_{12} \mathrm{O}_{40}$ /polymer composite; (e) SEM image of $\mathrm{W}_{10} \mathrm{O}_{32}\left(\mathrm{IPh}_{2}\right)_{4} /$ polymer composite; (f, g) TEM images of $\mathrm{W}_{10} \mathrm{O}_{32}\left(\mathrm{IPh}_{2}\right)_{4}$ /polymer composite at different scales and (h) TEM image of the prepared TMPTA based polymer without POMs.

Figures 6 (a), (b) and (c) correspond to the SEM images of $\mathrm{H}_{3} \mathrm{PMo}_{12} \mathrm{O}_{40}$ /polymer composite at different scales, showing the presence of spherical aggregates of different sizes ranging from $10 \mathrm{~nm}$ to $5 \mu \mathrm{m}$ in the polymer network. When zooming to a large aggregate of $\mathrm{H}_{3} \mathrm{PMo}_{12} \mathrm{O}_{40}$ (figure 6 (d)) we observe smaller spherical aggregates (about $10 \mathrm{~nm}$ of size). Also, Figures 6 (e) and (f) present TEM images of $\mathrm{W}_{10} \mathrm{O}_{32}\left(\mathrm{IPh}_{2}\right)_{4} /$ polymer composite showing the presence of different sizes of large and non-spherical $\mathrm{W}_{10} \mathrm{O}_{32}\left(\mathrm{IPh}_{2}\right)_{4}$ aggregates ranging from $0.1 \mu \mathrm{m}$ to $15 \mu \mathrm{m}$ which are dispersed randomly into the polymer matrix. TEM images (figure $6(\mathrm{~g}))$ taken on a zoomed $\mathrm{W}_{10} \mathrm{O}_{32}\left(\mathrm{IPh}_{2}\right)_{4}$ aggregate showed the presence of dark entities of 25 $\mathrm{nm}$ corresponding to $\mathrm{W}_{10} \mathrm{O}_{32}\left(\mathrm{IPh}_{2}\right)_{4}$ smaller aggregates. All these TEM/SEM images show i) the heterogeneous dispersion of POM particles in the polymer matrix, ii) the difference in sizes and shapes of the POM aggregates depending on the structure and the composition of the embedded POM. The POM structures will be detailed later in this work.

Moreover, Energy Dispersive X-ray (EDX) analysis of the composite was used to obtain additional information about the synthesized composites and more particularly about the dispersion of POMs and the potential presence of aggregates (See Figure 7). 

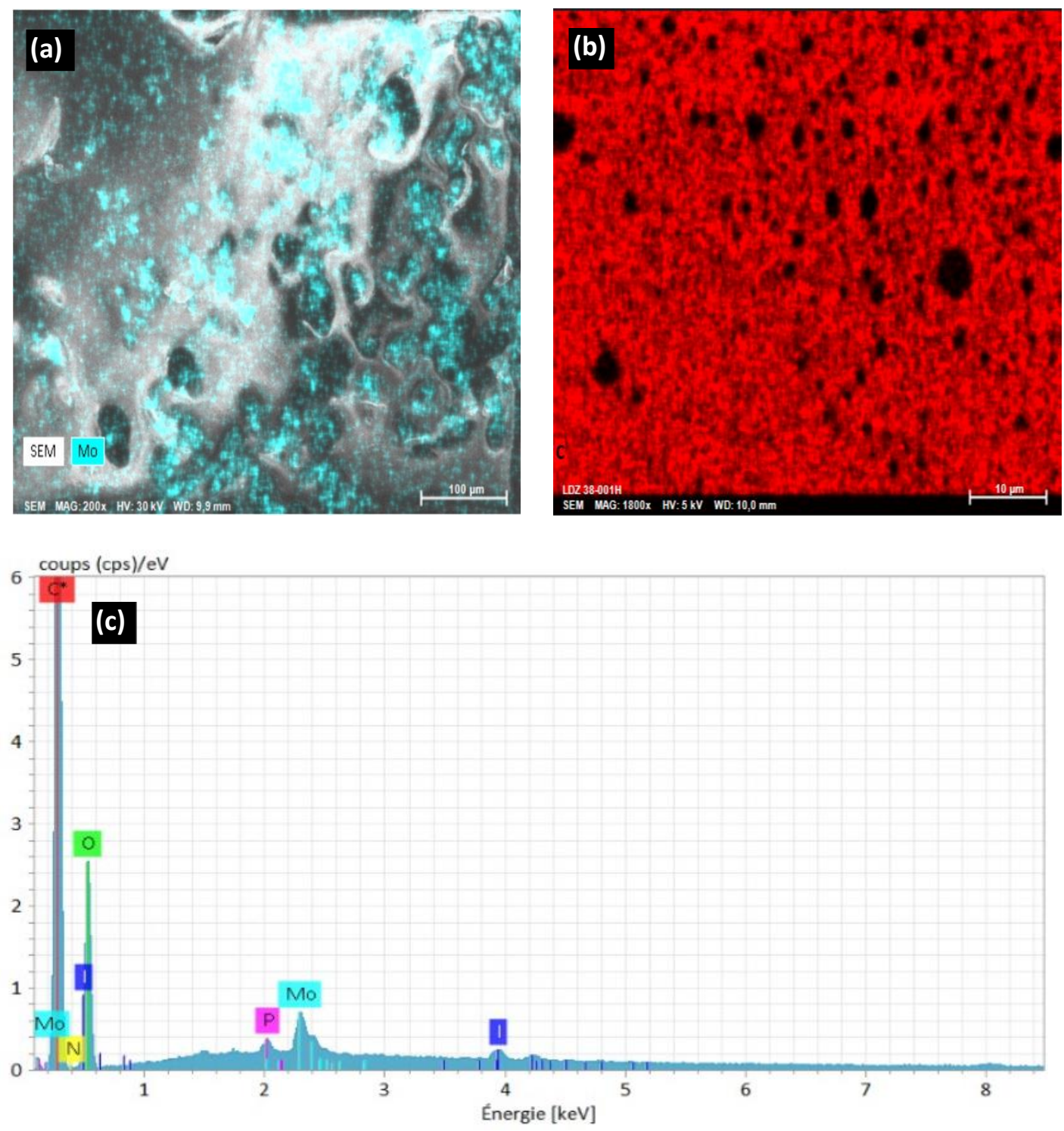

Figure 7. (a) SEM- EDX analyses of $\mathrm{H}_{3} \mathrm{PMo}_{12} \mathrm{O}_{40} /$ polymer composite, (b) SEM image of carbon seen in $\mathrm{H}_{3} \mathrm{PMo}_{12} \mathrm{O}_{40}$ /polymer composite (c) EDX analysis of $\mathrm{H}_{3} \mathrm{PMo}_{12} \mathrm{O}_{40}$ /polymer composite.

The overlap of SEM images and EDX analyses of Molybdate (Figure7(a)) for the $\mathrm{H}_{3} \mathrm{PMo}_{12} \mathrm{O}_{40}$ /polymer composite confirmed the non-homogeneous distribution of molybdate metals in the polymer matrix. The SEM image of the presence of carbon (in red forming the polymeric matrix) with the presence of different dark spots corresponding to the embedded aggregates of $\mathrm{H}_{3} \mathrm{PMo}_{12} \mathrm{O}_{40}$ (Figure 7(b)). The global chemical EDX analysis of the composite (Figure 7(c)) fully confirmed the presence of Molybdenum and phosphor coming from $\mathrm{H}_{3} \mathrm{PMo}_{12} \mathrm{O}_{40}$ nanoparticles, carbon from the polymer matrix (TMPTA) and oxygen from both $\mathrm{H}_{3} \mathrm{PMo}_{12} \mathrm{O}_{40}$ and polymer. Also, the presence of iodine is coming from the iodonium salt used for the photoinitiating system for the free radical polymerization of acrylates. 
Therefore, from SEM, TEM and EDX results, in-situ embedded POMs in a polymer matrix can be easily prepared by the photopolymerization. Moreover, the self-assembly of POMs could enhance the photocatalytic activity of these composites in removing different organic pollutants. ${ }^{4}$

\subsubsection{Structural and mechanical characterization}

\subsubsection{Surface properties and porosity}

The specific surface area is an important parameter for the evaluation of the porosity and the discussion of the heterogeneous catalysis behavior of the composites. Therefore, BET surface area and pore diameter were evaluated (Table 3 ).

Table 3. BET surface area and average pore diameter of different polyoxometalate powders, polymer and POM/polymer composites

\begin{tabular}{|c|c|c|}
\hline & $\begin{array}{c}\text { BET surface area } \\
\qquad\left(\mathrm{m}^{2} \cdot \mathrm{g}^{-1}\right)\end{array}$ & $\begin{array}{l}\text { Average pore } \\
\text { diameter }(\mathbf{n m})\end{array}$ \\
\hline TMPTA Polymer & 9.3 & 3.5 \\
\hline $\mathrm{W}_{10} \mathrm{O}_{32}\left(\mathrm{IPh}_{2}\right)_{4}$ & 3.5 & 16.6 \\
\hline $\mathrm{W}_{10} \mathrm{O}_{32}(\mathrm{TH})_{4}$ & 5.4 & 5.4 \\
\hline $\mathrm{H}_{3} \mathrm{PMO}_{12} \mathrm{O}_{40}$ & 14.3 & 6.2 \\
\hline $\mathrm{SiMo12}_{40}\left(\mathrm{IPh}_{2}\right)_{4}$ & 0.6 & 1,2 \\
\hline $\begin{array}{l}\mathrm{H}_{3} \mathrm{PMo12} \mathrm{O}_{40} / \mathrm{Polymer} \\
\text { Thick composite }\end{array}$ & 1.3 & 2.5 \\
\hline $\begin{array}{l}\mathrm{H}_{3} \mathrm{PMo}{ }_{12} \mathrm{O}_{40} / \mathrm{Polymer} \\
\text { Thin composite }\end{array}$ & 7.9 & 1.4 \\
\hline
\end{tabular}

The $\mathrm{N}_{2}$ adsorption analyses (Table 3 ) show the impact of the structure and the nature of the POM. In fact, The decatungstate $\mathrm{W}_{10} \mathrm{O}_{32}$ shows a specific surface around $3-5 \mathrm{~m}^{2} \cdot \mathrm{g}^{-1}$ whatever the counter-ions but the size of the latest will influence the pore size. However, for the polymolybdate $\mathrm{X}_{\mathrm{n}} \mathrm{Mo}_{12} \mathrm{O}_{40}$ composites, important differences are found with a specific surface area of $14 \mathrm{~m}^{2} \cdot \mathrm{g}^{-1}$ for $\mathrm{H}_{3} \mathrm{PMo}_{12} \mathrm{O}_{40}$ and no porosity in the case of $\mathrm{SiMo}_{12}\left(\mathrm{IPh}_{2}\right)_{4}$. This 
was also demonstrated by the $\mathrm{N}_{2}$ adsorption isotherms of different POMs (Figure 8) showing different behaviors.

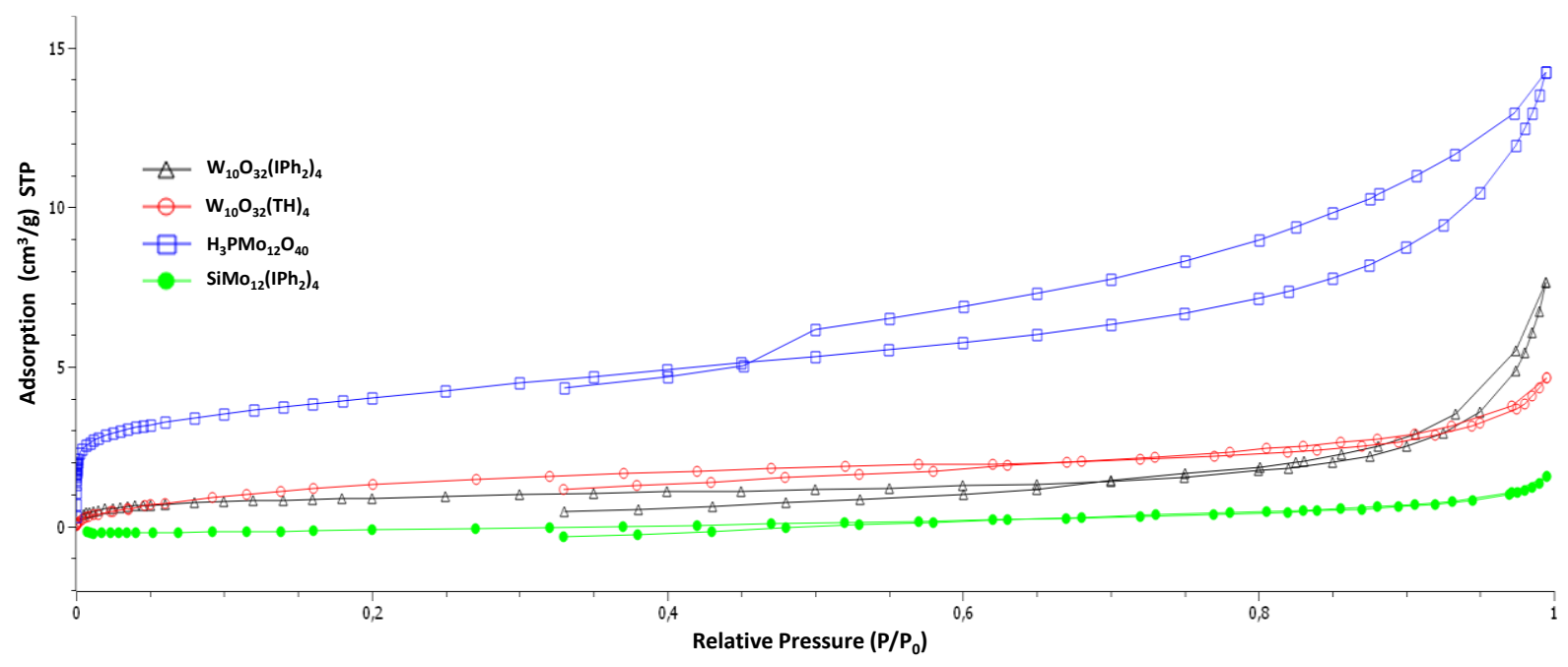

Figure 8. $\mathrm{N}_{2}$ adsorption isotherms for the different POMs.

In addition to a higher surface area, $\mathrm{H}_{3} \mathrm{PMo}_{12} \mathrm{O}_{40}$ shows a double porosity with a microporous part (pore inferior to $2 \mathrm{~nm}$ ) at low pressure and a mesoporous part which is indicated by the hysteresis. Inversely, $\mathrm{SiMo}_{12} \mathrm{O}_{40}\left(\mathrm{IPh}_{2}\right)_{4}$ has a relatively flat isotherm and a slight increase of the adsorption at high pressure corresponding to the inter-grain adsorption. In this case, the texture of this POM likely corresponds to large particles or aggregates without porosity.

In the case of decatungsate $\mathrm{W}_{10} \mathrm{O}_{32}$, the $\mathrm{N}_{2}$ isotherms present a slight increase which is relatively similar whatever the pressure and the composition (Figure 8). Nevertheless, in the function of the latest, we can observe an increase in the adsorption at high pressure more or less important: more the increase is important, more hysteresis seems to be present. This behavior is probably linked to the size of the particles and their aggregations. Thus, the different results suggest that $\mathrm{W}_{10} \mathrm{O}_{32}\left(\mathrm{IPh}_{2}\right)_{4}$ is on the form of weakly porous particles present on the form of aggregations (as seen by SEM, Figure 6 (e)) and the size of inter-grain volumes corresponds to large mesopores. In the case of $\mathrm{W}_{10} \mathrm{O}_{32}(\mathrm{TH})_{4}$, the porosity is probably similar but the particles are under the form of more opened aggregates (macropores) or larger particles. Thus, herein, we can observe again the influence of the composition of a polyoxometalate (specially the counter ion) on its porosity and its structure.

For the neat polymer, the pore size distribution according to the Density Functional Theory (DFT) (Figure 9) shows the presence of a large porosity with a maximum value of about 
$4.8 \mathrm{~nm}$. This result completes the reported value in Table 3 indicating an average pore diameter of $3.5 \mathrm{~nm}$ for the polymer. Based on that, we can also explain the obtained swelling degree of the polymer which is $10 \%$ due to its porosity. At high pressure, we can observe an increase that can be explained by a swelling of the porosity by the nitrogen. ${ }^{54}$

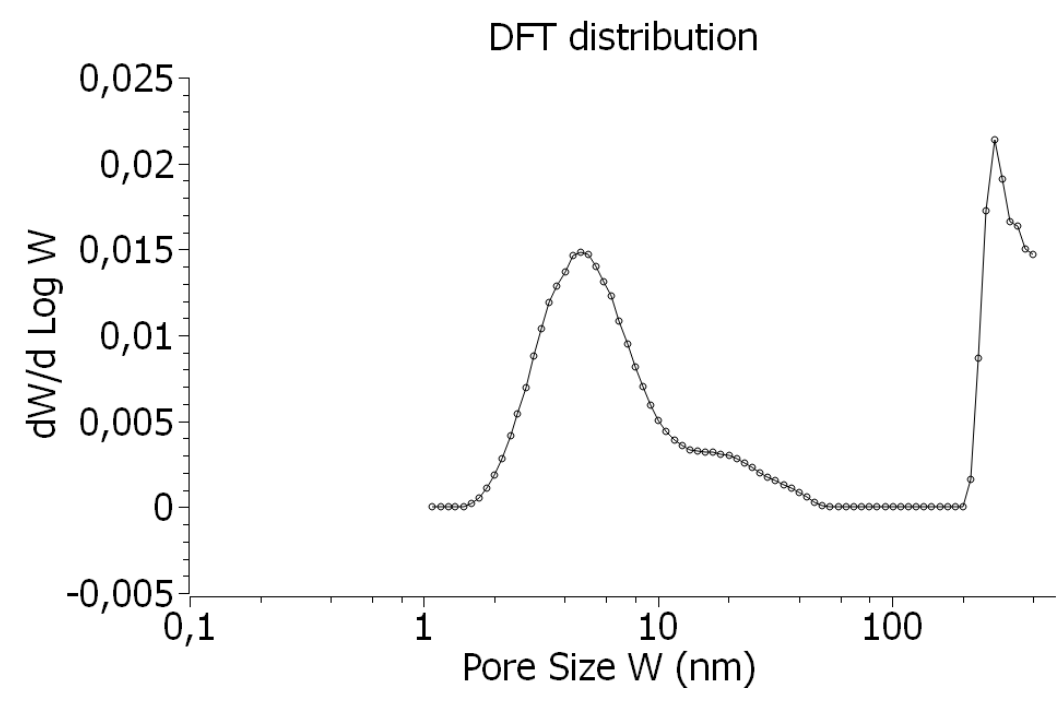

Figure 9. The neat polymer pore size distribution according to DFT.

Concerning the POM/polymer composites, the polymer specific surface area $\left(9.3 \mathrm{~m}^{2} \cdot \mathrm{g}^{-1}\right)$ and pore diameter decreased significantly by the introduction of POMs nanoparticles into the polymer (Table 3$)$. Indeed, in the case of $1 \% \mathrm{H}_{3} \mathrm{PMo}_{12} \mathrm{O}_{40} /$ polymer thick composite $(1.3 \mathrm{~mm})$ BET specific surface area fall to $1.3 \mathrm{~m}^{2} . \mathrm{g}^{-1}$ with an average pore diameter of $2.55 \mathrm{~nm}$. Such a decrease in BET surface area and pore diameter of the polymer could be explained by the fact that incorporated POMs aggregates are confined with the polymer channels as seen in Figure 7(b). Actually, when embedded into the polymer network the specific surface area of $\mathrm{H}_{3} \mathrm{PMo}_{12} \mathrm{O}_{40}\left(14.3 \mathrm{~m}^{2} . \mathrm{g}^{-1}\right)$ falls to $1.3 \mathrm{~m}^{2} \cdot \mathrm{g}^{-1}$ in the case of $1 \% \mathrm{H}_{3} \mathrm{PMo}_{12} \mathrm{O}_{40} /$ polymer thick composite and to $7.9 \mathrm{~m}^{2} \cdot \mathrm{g}^{-1}$ in the case of $1 \% \mathrm{H}_{3} \mathrm{PMo}_{12} \mathrm{O}_{40}$ /polymer thin composite $(25 \mu \mathrm{m})$. These results demonstrate that the incorporation of POMs nanoparticles into the polymer matrix decreases the specific surface area and pore size (Table 3) of both the polymer and the POMs nanoparticles due to the important crosslinking density of the polymer matrix after polymerization process as shown by swelling experiments. Thus, the higher are the thickness and the crosslinking density of the polymer network, the lower are the specific surface area and pore size of the obtained POM/polymer composites. This fact was also reported by Zhang and 
his collaborators ${ }^{55}$ indicating that introduction of $\left(\left[\left(\mathrm{Eu}_{2} \mathrm{PW}_{10} \mathrm{O}_{38}\right)_{4}\left(\mathrm{~W}_{3} \mathrm{O}_{8}\left(\mathrm{H}_{2} \mathrm{O}\right)_{2}(\mathrm{OH})_{4}\right)\right]_{22}\right)$ into Polycrystalline aluminosilicate polymer decreased the BET surface area and the pore volume.

For further investigation of the surface properties, topological characterization of the polymer and $\mathrm{W}_{10} \mathrm{O}_{32}\left(\mathrm{IPh}_{2}\right)_{4}$ /polymer was realized using Atomic Force Microscopy (AFM) with the Peak-Force QNM imaging mode. Figure 10 shows the obtained topographical images.
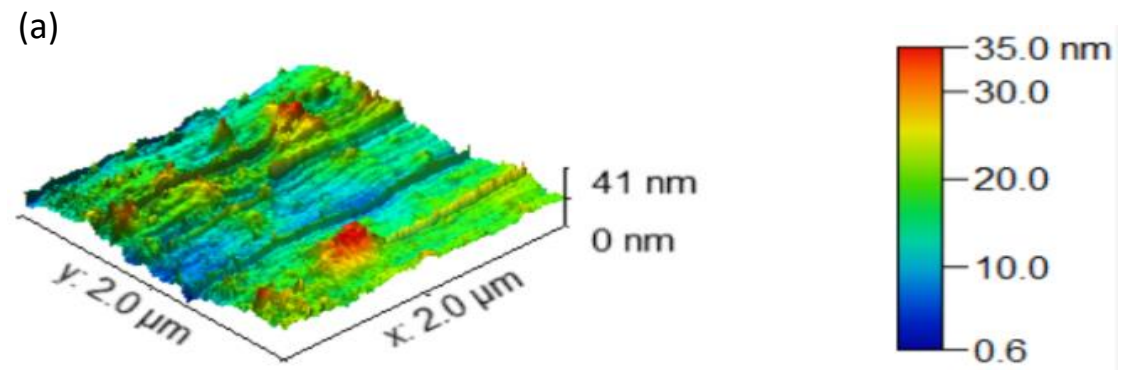

(b)
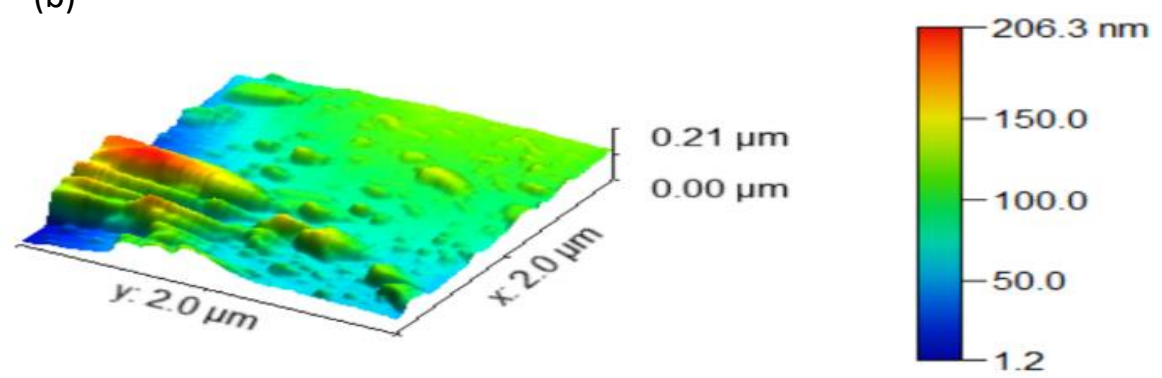

Figure 10. 3D AFM height images of (a) the polymer without POM and (b) the $\mathrm{W}_{10} \mathrm{O}_{32}\left(\mathrm{IPh}_{2}\right)_{4} /$ polymer composite.

AFM recorded topology of the polymer (see Figure 10 (a)) showed a rather rough surface with the presence of edges and grooves where the height was ranging from [0.6-35 nm] and 5 $\mathrm{nm}$ as a roughness average value. This rugosity could explain the obtained porous structures of polymer obtained by BET surface area (Table 3).

However, $\mathrm{W}_{10} \mathrm{O}_{32}\left(\mathrm{IPh}_{2}\right)_{4} /$ polymer composite did not present the same surface topology (Figure 10 (b)). Indeed, a much higher surface rugosity was observed i.e. an important difference on the surface height that was ranging from $[1.2-206.3 \mathrm{~nm}]$ was observed with a roughness average value of $199 \mathrm{~nm}$. The observed difference of rugosity between the polymer and the composite could be attributed to the presence of $\mathrm{W}_{10} \mathrm{O}_{32}\left(\mathrm{IPh}_{2}\right)_{4}$ aggregates at the surface of the composite. 


\subsubsection{Mechanical properties}

Mechanical properties of the composites were also studied by AFM (Peak-Force QNM imaging mode). Figure 11 shows the recorded topology of the elastic modulus on the surface of the composite for the $\mathrm{W}_{10} \mathrm{O}_{32}\left(\mathrm{IPh}_{2}\right)_{4} /$ polymer composite.
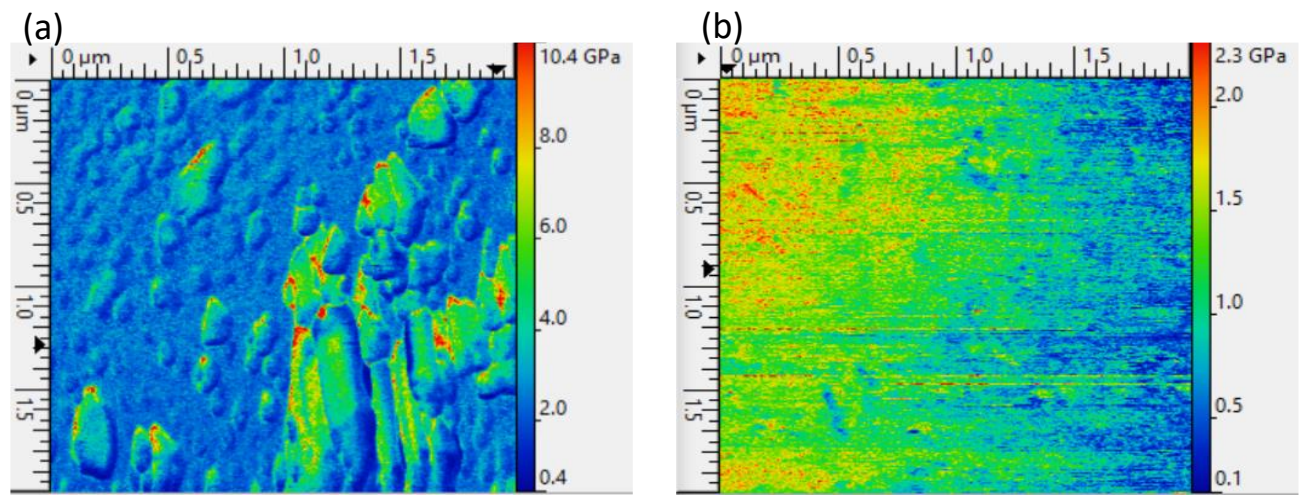

(c)

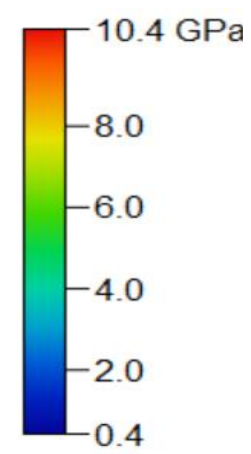

Figure 11. AFM stiffness images (Young modulus) of (a) $\mathrm{W}_{10} \mathrm{O}_{32}\left(\mathrm{IPh}_{2}\right)_{4} /$ polymer composite and (b) the polymer without POM. (c) 3D AFM stiffness image (Young modulus) of the of $\mathrm{W}_{10} \mathrm{O}_{32}\left(\mathrm{IPh}_{2}\right)_{4} /$ polymer composite.

From the AFM images (Figure 12), it is obvious that $\mathrm{W}_{10} \mathrm{O}_{32}\left(\mathrm{IPh}_{2}\right)_{4} /$ polymer composite presents a non-homogeneous surface rigidity. Compared to the polymer elastic modulus ranging from $[0.1-2.3 \mathrm{GPa}]$ with an average value of $1.14 \mathrm{GPa}$, the composite $\mathrm{W}_{10} \mathrm{O}_{32}\left(\mathrm{IPh}_{2}\right)_{4} /$ polymer presented a higher elastic modulus ranging from [0.4 - $\left.10.6 \mathrm{GPa}\right]$ with an average value of $2.9 \mathrm{GPa}$. This improvement of the rigidity of the composite (reinforcement property) is attributed to the presence of $\mathrm{W}_{10} \mathrm{O}_{32}\left(\mathrm{IPh}_{2}\right)_{4}$ nanoparticles into the composite.

Moreover, by comparing 3D AFM visualization of the surface topology (Figure 10 (b)) and the 3D AFM visualization of the mechanical properties (Figure 11 (c)), it can be assumed that the highest elastic modulus was concentrated on $\mathrm{W}_{10} \mathrm{O}_{32}\left(\mathrm{IPh}_{2}\right)_{4}$ aggregates. Therefore, the 
presence of $\mathrm{W}_{10} \mathrm{O}_{32}\left(\mathrm{IPh}_{2}\right)_{4}$ nanoparticles at the polymer surface improves the rigidity of the obtained composites.

For further information, the bulk mechanical properties of the composites were evaluated using Dynamic Mechanical analysis DMA experiments. The obtained values of dynamic storage modulus $\mathrm{G}^{\prime}$ and dynamic loss modulus $\mathrm{G}$ ' at $25^{\circ} \mathrm{C}$ are presented in Table 4.

Table 4. Dynamic storage modulus (G') and dynamic loss modulus (G') at $25^{\circ} \mathrm{C}$ of the different composites vs. the TMPTA based polymer.

\begin{tabular}{|c|c|c|}
\hline Composition & $\begin{array}{l}\text { Dynamic storage } \\
\text { modulus G'(MPa) }\end{array}$ & $\begin{array}{c}\text { Dynamic loss modulus G' } \\
\text { (MPa) }\end{array}$ \\
\hline Polymer & 100 & 20 \\
\hline Composite $1 \% \mathrm{H}_{3} \mathrm{PMo12}_{40}$ & 90 & 8 \\
\hline Composite $3 \% \mathrm{H}_{3} \mathrm{PMo}_{12} \mathrm{O}_{40}$ & 95 & 8 \\
\hline Composite $1 \% \mathrm{~W}_{10} \mathrm{O}_{32}\left(\mathrm{IPh}_{2}\right)_{4}$ & 100 & 16 \\
\hline Composite $3 \% \mathrm{~W}_{10} \mathrm{O}_{32}\left(\mathrm{IPh}_{2}\right)_{4}$ & 95 & 9 \\
\hline
\end{tabular}

In all cases, the dynamic storage modulus $G^{\prime}$ is higher than the dynamic loss modulus G'for the different composites suggesting that both the neat TMPTA based polymer and the composites are more solid-like property with high mechanical rigidity. This is again in agreement with the low swelling degree (Table 1) and high crosslinking density of the polymeric network of the polymer and different composites. Moreover, G' values do not present a significant variation with or without POM this can be ascribed to its low content (1 or 3\%) that does not change this bulk property but mainly the surface properties (see above the AFM experiments).

However, the dynamic loss modulus G' decreases in the case of composites compared to the polymer (Table 4). This is explained by the addition of POMs nanoparticles that reduces the mobility of polymer chains. Actually, in the absence of POMs nanoparticles, polymer chains respond more easily to the applied stress. By adding the fillers (POMs) the movement of the polymer chains is reduced and therefore the stress transfer in the matrix is decreased. 


\subsection{Composites optical properties}

The present POM/polymer composites were developed for specific photocatalytic applications, consequently, it was important to estimate their energy band gap. Therefore, their optical properties were examined through UV-vis diffuse reflectance spectra and the results are shown in Figure 12 (See Table 5).
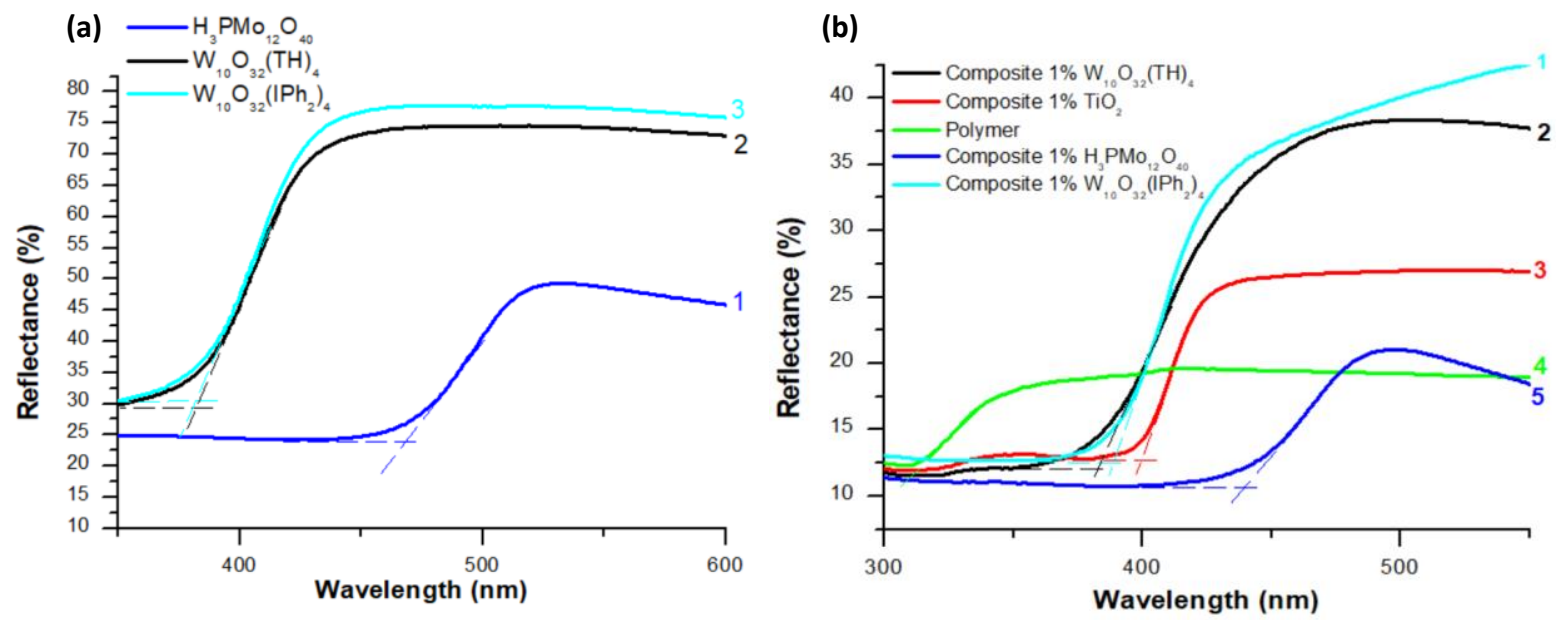

Figure 12. (a) UV-vis diffuse reflectance spectra of (1) $\mathrm{H}_{3} \mathrm{PMo}_{12} \mathrm{O}_{40}$ powder and (2) $\mathrm{W}_{10} \mathrm{O}_{32}(\mathrm{TH})_{4}$ powder and (3) $\mathrm{W}_{10} \mathrm{O}_{32}\left(\mathrm{IPh}_{2}\right)_{4}$ powder; (b) $\mathrm{UV}$-vis diffuse reflectance spectra of (1) $1 \% \mathrm{~W}_{10} \mathrm{O}_{32}\left(\mathrm{IPh}_{2}\right)_{4} /$ polymer composite, (2) $1 \% \mathrm{~W}_{10} \mathrm{O}_{32}(\mathrm{TH})_{4} /$ polymer composite, (3) $1 \%$ $\mathrm{TiO}_{2} /$ polymer composite; (4) neat polymer and (5) $1 \% \mathrm{H}_{3} \mathrm{PMo}_{12} \mathrm{O}_{40} /$ polymer composite.

Table 5. Bandgap energy values of different POMs and synthesized composites (using $1 \%$ of fillers in TMPTA)

\begin{tabular}{cc}
\hline Composite & Bandgap Energy $(\mathbf{e V})$ \\
\hline Polymer & 3.9 \\
\hline $\mathrm{H}_{3} \mathrm{PMo}_{12} \mathrm{O}_{40}$ (Powder) & 2.6 \\
\hline $\mathrm{W}_{10} \mathrm{O}_{32}(\mathrm{TH})_{4}($ Powder $)$ & 3.3 \\
\hline $\mathrm{W}_{10} \mathrm{O}_{32}\left(\mathrm{IPh}_{2}\right)_{4}($ Powder $)$ & 3.3 \\
\hline $\mathrm{H}_{3} \mathrm{PMo}_{12} \mathrm{O}_{40}$ composite & 2.8 \\
\hline $\mathrm{W}_{10} \mathrm{O}_{32}(\mathrm{TH})_{4}$ composite & 3.2 \\
\hline $\mathrm{W}_{10} \mathrm{O}_{32}\left(\mathrm{IPh}_{2}\right)_{4}$ composite & 3.2 \\
\hline $\mathrm{TiO}_{2}$ composite & 3.1 \\
\hline
\end{tabular}


The bandgap was extracted from the reflectance spectra as the intercept of the slope with the $\mathrm{x}$-axis as shown in Figure 12 (Table 5). Remarkably, the $\mathrm{H}_{3} \mathrm{PMo}_{12} \mathrm{O}_{40}$ (powder) and $\mathrm{H}_{3} \mathrm{PMo}_{12} \mathrm{O}_{40} /$ polymer composite could induce a bathochromic shift of the absorption compared to the well-established $\mathrm{TiO}_{2}$ photocatalyst. Since the photocatalytic performance of a photocatalyst is directly governed by its bandgap or its absorption properties, a good matching between the absorption properties of the composites and the emission spectrum of the light source is always required. Here, $\mathrm{H}_{3} \mathrm{PMo}_{12} \mathrm{O}_{40}$ allowed a better overlap than $\mathrm{TiO}_{2}$ with the visible light.

\subsection{Composite reactivity under photolysis and regeneration}

To further study the reactivity of the composites under photolysis using LED irradiation, Electron Spin Resonance (ESR) experiments were carried out for the $1 \% \mathrm{H}_{3} \mathrm{PMO}_{12} \mathrm{O}_{40}$ polymer composite under light LED irradiation @ 405 nm. The obtained ESR spectra (see Figure 13) suggest the generation of transient species at the composite surface after a long irradiation time (typically 3 hours).

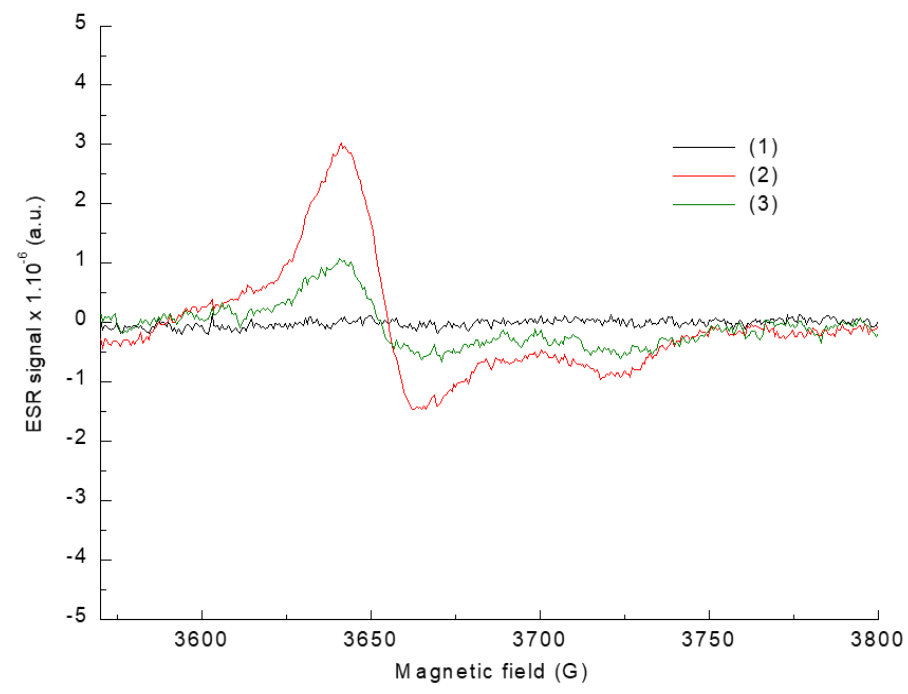

Figure 13. Experimental ESR spectra for $1 \% \mathrm{H}_{3} \mathrm{PMO}_{12} \mathrm{O}_{40} /$ polymer composite (1) taken before irradiation, (2) after $3 \mathrm{~h}$ of irradiation with a LED@405 nm in an aqueous solution of Rose Bengal (10 ppm) and (3) after 5 days kept in dark.

Just before the irradiation of the composite, no ESR signal was observed (Figure 13, curve 1). Whereas a clear signal was observed between $3600 \mathrm{G}$ and $3800 \mathrm{G}$ after $3 \mathrm{~h}$ of irradiation (See Figure 13, curve 2). These signals could be attributed to Mo (V) according to the g value, which is around 1.92, and the multiplet character of the ESR transition. Some of the Mo natural isotopes exhibit a nuclear spin of $5 / 2$. This ESR signal may arise from the photoreduction of Mo (VI) while exposed to light irradiation as previously reported. ${ }^{56}$ 
Finally, ESR spectra recorded after five days of storage in the dark showed a clear decrease in the peak (figure13, curve 3 vs. curve 2). This result demonstrates that the regeneration of Mo species is possible upon storage in the presence of air. Therefore, the observed reoxidation of the composite is attributed to the reoxidation of embedded $\mathrm{H}_{3} \mathrm{PMO}_{12} \mathrm{O}_{40}$ by dioxygen. This is in agreement with the reusable character found in previous works. $^{49}$

Thus, POM/polymer composites exhibit light sensitivity after exposure to LED@405 nm irradiation by reducing the metal oxide of the incorporated POM nanoparticles and could be regenerated by $\mathrm{O}_{2}$. This is a particularly important result for the potential reuse of the composite in photocatalytic applications.

\section{Conclusion:}

In the present paper, a simple and mild approach was introduced to prepare inorganic/organic hybrid composites based on polyoxometalates by photopolymerization under visible light using Light Emitting Diodes LED@405 nm as a cheap and safe irradiation source. The new proposed POM/polymer composites were characterized by several techniques. More particularly, SEM, TEM and EDX revealed the successful embedding of POMs nanoparticles which are present in aggregates in the polymer matrix. Indeed, self-assembly of POMs nanoparticles at the surface improves its mechanical properties as shown by AFM analysis. Moreover, hybrid POM/Polymer composites present high rigidity, a relatively low surface area (BET surface area is lower than $10 \mathrm{~m}^{2} \cdot \mathrm{g}^{-1}$ ), exhibit redox properties and a regeneration ability under air.

We demonstrated also the efficient photocatalytic ability of developed composites for the color removal of erythrosine B and rose Bengal using soft LED@375 nm irradiation reaching respectively $80 \%$ and $90 \%$ after $2 \mathrm{~h}$ of irradiation in the presence of only $\mathrm{H}_{3} \mathrm{PMO}_{12} \mathrm{O}_{40} /$ polymer composite. In general, the proposed POM/polymer composites can open up new routes in the field of inorganic/polymer composites with important properties and applications in heterogeneous catalysis and organic pollutant removal. The use of the composites for the degradation of emergent pollutants will be proposed in forthcoming papers. 


\section{References:}

(1) Casañ-Pastor, N.; Gómez-Romero, P. Polyoxometalates: From Inorganic Chemistry to Materials Science. Frontiers in Bioscience 2004, 9, 1759-1770.

(2) Genovese, M.; Lian, K. Polyoxometalate Modified Inorganic-Organic Nanocomposite Materials for Energy Storage Applications: A Review. Current Opinion in Solid State and Materials Science 2015, $19 \quad$ (2), $126-137$. https://doi.org/10.1016/j.cossms.2014.12.002.

(3) Althues, H.; Henle, J.; Kaskel, S. Functional Inorganic Nanofillers for Transparent Polymers. Chem. Soc. Rev. 2007, 36 (9), 1454. https://doi.org/10.1039/b608177k.

(4) Qi, W.; Wu, L. Polyoxometalate/Polymer Hybrid Materials: Fabrication and Properties. Polym. Int. 2009, 58 (11), 1217-1225. https://doi.org/10.1002/pi.2654.

(5) Pope, M. T.; Müller, A. Introduction to Polyoxometalate Chemistry: From Topology via Self-Assembly to Applications. Polyoxometalate Chemistry From Topology via SelfAssembly to Applications 2002, 1-6. https://doi.org/10.1007/0-306-47625-8_1.

(6) Papaconstantinou, E. Photochemistry of Polyoxometallates of Molybdenum and Tungsten and/or Vanadium. Chemical Society Reviews 1989, 18, 1. https://doi.org/10.1039/cs9891800001.

(7) Long, D.-L.; Cronin, L. Towards Polyoxometalate-Integrated Nanosystems. Chem. Eur. J. 2006, 12 (14), 3698-3706. https://doi.org/10.1002/chem.200501002.

(8) Hiskia, A.; Mylonas, A.; Papaconstantinou, E. Comparison of the Photoredox Properties of Polyoxometallates and Semiconducting Particles. Chemical Society Reviews 2001, 30 (1), 62-69. https://doi.org/10.1039/a905675k.

(9) Sadakane, M.; Steckhan, E. Electrochemical Properties of Polyoxometalates as Electrocatalysts. Chemical Reviews 1998, $98 \quad$ (1), 219-238. https://doi.org/10.1021/cr960403a.

(10) Hiskia, A.; Papaconstantinou, E. Photocatalytic Oxidation of Organic Compounds by Polyoxometalates of Molybdenum and Tungsten. Catalyst Regeneration by Dioxygen. Inorganic Chemistry 1992, 31 (2), 163-167. https://doi.org/10.1021/ic00028a007.

(11) Orlandi, M.; Argazzi, R.; Sartorel, A.; Carraro, M.; Scorrano, G.; Bonchio, M.; Scandola, F. Ruthenium Polyoxometalate Water Splitting Catalyst: Very Fast Hole Scavenging from Photogenerated Oxidants. Chem. Commun. 2010, 46 (18), 3152-3154. https://doi.org/10.1039/B926823E.

(12) Papaconstantinou, E.; Argitis, P.; Dimoticali, D.; Hiskia, A.; Ioannidis, A. Photocatalytic Oxidation of Organic Compounds with Heteropoly Electrolytes. Aspects on Photochemical Utilization of Solar Energy. In Homogeneous and Heterogeneous Photocatalysis; Pelizzetti, E., Serpone, N., Eds.; NATO ASI Series; Springer Netherlands: Dordrecht, 1986; pp 415-431. https://doi.org/10.1007/978-94-009-46422_25.

(13) Long, D.-L.; Tsunashima, R.; Cronin, L. Polyoxometalates: Building Blocks for Functional Nanoscale Systems. Angew. Chem. Int. Ed. 2010, 49 (10), 1736-1758. https://doi.org/10.1002/anie.200902483.

(14) Liu, C.-G.; Zheng, T.; Liu, S.; Zhang, H.-Y. Photodegradation of Malachite Green Dye Catalyzed by Keggin-Type Polyoxometalates under Visible-Light Irradiation: Transition Metal Substituted Effects. Journal of Molecular Structure 2016, 1110, 44-52. https://doi.org/10.1016/j.molstruc.2016.01.015.

(15) Jayaraj, S. K.; Sadishkumar, V.; Arun, T.; Thangadurai, P. Enhanced Photocatalytic Activity of V 2 O 5 Nanorods for the Photodegradation of Organic Dyes: A Detailed Understanding of the Mechanism and Their Antibacterial Activity. Materials Science in 
Semiconductor

Processing

2018,

85 ,

$122-133$.

https://doi.org/10.1016/j.mssp.2018.06.006.

(16) Rafqah, S.; Chung, P. W.-W.; Forano, C.; Sarakha, M. Photocatalytic Degradation of Metsulfuron Methyl in Aqueous Solution by Decatungstate Anions. Journal of Photochemistry and Photobiology A: Chemistry 2008, 199 (2-3), 297-302. https://doi.org/10.1016/j.jphotochem.2008.06.012.

(17) Antonaraki, S.; Triantis, T. M.; Papaconstantinou, E.; Hiskia, A. Photocatalytic Degradation of Lindane by Polyoxometalates: Intermediates and Mechanistic Aspects. Catalysis Today 2010, 151 (1-2), 119-124. https://doi.org/10.1016/j.cattod.2010.02.017.

(18) Texier, I.; Giannotti, C.; Malato, S.; Richter, C.; Delaire, J. Solar Photodegradation of Pesticides in Water by Sodium Decatungstate. Catalysis Today 1999, 11.

(19) Gao, H.; Wu, H.; Lian, K. A Comparative Study of Polymer Electrolytes for Ultrahigh Rate Applications. Electrochemistry Communications 2012, 17, 48-51. https://doi.org/10.1016/j.elecom.2012.01.025.

(20) Liu, S.; Kurth, D. G.; Möhwald, H.; Volkmer, D. A Thin-Film Electrochromic Device Based on a Polyoxometalate Cluster. 4.

(21) Hayashi, H. The Properties of Heteropoly Acids and the Conversion of Methanol to Hydrocarbons. Journal of Catalysis 1982, $77 \quad$ (2), 473-484. https://doi.org/10.1016/0021-9517(82)90187-7.

(22) Ozer, R. R.; Ferry, J. L. Investigation of the Photocatalytic Activity of TiO2-Polyoxometalate Systems. Environmental Science \& Technology 2001, 35 (15), 3242-3246. https://doi.org/10.1021/es0106568.

(23) Guo, Y.; Wang, Y.; Hu, C.; Wang, Y.; Wang, E.; Zhou, Y.; Feng, S. Microporous Polyoxometalates POMs/SiO2: Synthesis and Photocatalytic Degradation of Aqueous Organocholorine Pesticides. Chem.Mater. 2000, 12 (11), 3501-3508. https://doi.org/10.1021/cm000074+.

(24) Neumann, R.; Levin, M. Selective Aerobic Oxidative Dehydrogenation of Alcohols and Amines Catalyzed by a Supported Molybdenum-Vanadium Heteropolyanion Salt Na5PMo2V2O40. The Journal of Organic Chemistry 1991, 56 (19), 5707-5710. https://doi.org/10.1021/jo00019a047.

(25) Izumi, Y.; Urabe, K. Catalysis of Heteropoly Acids Entrapped in Activated Carbon. Chemistry Letters 1981, 10 (5), 663-666. https://doi.org/10.1246/cl.1981.663.

(26) Zhang, D.; Zhang, Y.; Ma, H.; Yan, H.; Song, Y. Fabrication of a 12-Tungstophosphate and Cadmium Oxide Composite Film and Its Properties. Materials Chemistry and Physics 2014, 144 (3), 369-376. https://doi.org/10.1016/j.matchemphys.2014.01.004.

(27) Feng, C.; Xu, G.; Liu, X. Photocatalytic Degradation of Imidacloprid by Composite Catalysts H3PW12O40/La-TiO2. Journal of Rare Earths 2013, 31 (1), 44-48. https://doi.org/10.1016/S1002-0721(12)60232-4.

(28) Chen, J.-J. J.; Barteau, M. A. Molybdenum Polyoxometalates as Active Species for Energy Storage in Non-Aqueous Media. Journal of Energy Storage 2017, 13, 255-261. https://doi.org/10.1016/j.est.2017.07.017.

(29) Rani, M.; Shanker, U. Sun-Light Driven Rapid Photocatalytic Degradation of Methylene Blue by Poly(Methyl Methacrylate)/Metal Oxide Nanocomposites. Colloids and Surfaces A: Physicochemical and Engineering Aspects 2018, 559, 136-147. https://doi.org/10.1016/j.colsurfa.2018.09.040.

(30) Kishore, P. S.; Viswanathan, B.; Varadarajan, T. K. Synthesis and Characterization of Metal Nanoparticle Embedded Conducting Polymer-Polyoxometalate Composites. Nanoscale Res Lett 2008, 3 (1), 14-20. https://doi.org/10.1007/s11671-007-9107-z.

(31) Han, F.; Kambala, V. S. R.; Srinivasan, M.; Rajarathnam, D.; Naidu, R. Tailored Titanium Dioxide Photocatalysts for the Degradation of Organic Dyes in Wastewater 
Treatment: A Review. Applied Catalysis A: General 2009, 359 (1-2), 25-40. https://doi.org/10.1016/j.apcata.2009.02.043.

(32) Niu, P.; Hao, J. Efficient Degradation of Organic Dyes by Titanium DioxideSilicotungstic Acid Nanocomposite Films: Influence of Inorganic Salts and Surfactants. Colloids and Surfaces A: Physicochemical and Engineering Aspects 2014, 443, 501507.

(33) Watcharenwong, A.; Chanmanee, W.; De Tacconi, N. R.; Chenthamarakshan, C. R.; Kajitvichyanukul, P.; Rajeshwar, K. Self-Organized TiO 2 Nanotube Arrays by Anodization of $\mathrm{Ti}$ Substrate: Effect of Anodization Time, Voltage and Medium Composition on Oxide Morphology and Photoelectrochemical Response. Journal of Materials Research 2007, 22 (11), 3186-3195.

(34) Bessekhouad, Y.; Chaoui, N.; Trzpit, M.; Ghazzal, N.; Robert, D.; Weber, J. V. UV-Vis versus Visible Degradation of Acid Orange II in a Coupled CdS/TiO2 Semiconductors Suspension. Journal of Photochemistry and Photobiology A: Chemistry 2006, 183 (12), 218-224.

(35) Feng, J.; Wong, R. S.; Hu, X.; Yue, P. L. Discoloration and Mineralization of Orange II by Using $\mathrm{Fe} 3+-$ Doped $\mathrm{TiO} 2$ and Bentonite Clay-Based Fe Nanocatalysts. Catalysis Today 2004, 98 (3), 441-446.

(36) Miyauchi, M.; Nakajima, A.; Fujishima, A.; Hashimoto, K.; Watanabe, T. Photoinduced Surface Reactions on $\mathrm{TiO} 2$ and SrTiO3 Films: Photocatalytic Oxidation and Photoinduced Hydrophilicity. Chemistry of Materials 2000, 12 (1), 3-5.

(37) Brown, G. T.; Darwent, J. R. Photoreduction of Methyl Orange Sensitized by Colloidal Titanium Dioxide. Journal of the Chemical Society, Faraday Transactions 1: Physical Chemistry in Condensed Phases 1984, 80 (6), 1631-1643.

(38) Yoneyama, H.; Toyoguchi, Y.; Tamura, H. Reduction of Methylene Blue on Illuminated Titanium Dioxide in Methanolic and Aqueous Solutions. The Journal of Physical Chemistry 1972, 76 (23), 3460-3464.

(39) Matthews, R. W. Photooxidation of Organic Impurities in Water Using Thin Films of Titanium Dioxide. Journal of Physical Chemistry 1987, 91 (12), 3328-3333.

(40) Kiwi, J. Role of Oxygen at the TiO2 Interface during Photodegradation of Biologically Difficult-to-Degrade Anthraquinone-Sulfonate Dyes. Environmental Toxicology and Chemistry: An International Journal 1994, 13 (10), 1569-1575.

(41) Guo, Y.; Hu, C. Heterogeneous Photocatalysis by Solid Polyoxometalates. Journal of Molecular Catalysis A: Chemical 2007, 262 (1-2), 136-148. https://doi.org/10.1016/j.molcata.2006.08.039.

(42) Changgen, F.; Xiaoxi, Z.; Xia, L. I. U. Study on Photodegradation of Azo Dye by Polyoxometalates/Polyvinyl Alcohol. Journal of Rare Earths 2009, 27 (5), 717-722.

(43) You, Y.; Gao, S.; Yang, Z.; Cao, M.; Cao, R. Facile Synthesis of PolyoxometalateThionine Composite via Direct Precipitation Method and Its Photocatalytic Activity for Degradation of Rhodamine B under Visible Light. Journal of colloid and interface science 2012, 365 (1), 198-203.

(44) Li, H.; Gao, S.; Cao, M.; Cao, R. Self-Assembly of Polyoxometalate-Thionine Multilayer Films on Magnetic Microspheres as Photocatalyst for Methyl Orange Degradation under Visible Light Irradiation. Journal of colloid and interface science 2013, 394, 434-440.

(45) Li, T.; Gao, S.; Li, F.; Cao, R. Photocatalytic Property of a Keggin-Type Polyoxometalates-Containing Bilayer System for Degradation Organic Dye Model. Journal of colloid and interface science 2009, 338 (2), 500-505.

(46) Dendukuri, D.; Panda, P.; Haghgooie, R.; Kim, J. M.; Hatton, T. A.; Doyle, P. S. Modeling of Oxygen-Inhibited Free Radical Photopolymerization in a PDMS 
Microfluidic Device. Macromolecules 2008, $41 \quad$ (22), $8547-8556$. https://doi.org/10.1021/ma801219w.

(47) Rocchiccioli-Deltcheff, C.; Fournier, M.; Franck, R.; Thouvenot, R. Vibrational Investigations of Polyoxometalates. 2. Evidence for Anion-Anion Interactions in Molybdenum(VI) and Tungsten(VI) Compounds Related to the Keggin Structure. Inorganic Chemistry 1983, 22 (2), 207-216. https://doi.org/10.1021/ic00144a006.

(48) Mokbel, H.; Xiao, P.; Simonnet-Jégat, C.; Dumur, F.; Gigmes, D.; Toufaily, J.; Hamieh, T.; Fouassier, J. P.; Lalevée, J. Iodonium-Polyoxometalate and ThianthreniumPolyoxometalate as New One-Component UV Photoinitiators for Radical and Cationic Polymerization. J. Polym. Sci. Part A: Polym. Chem. 2015, 53 (8), 981-989. https://doi.org/10.1002/pola.27526.

(49) Ghali, M.; Brahmi, C.; Benltifa, M.; Dumur, F.; Duval, S.; Simonnet-Jégat, C.; MorletSavary, F.; Jellali, S.; Bousselmi, L.; Lalevée, J. New Hybrid Polyoxometalate/Polymer Composites for Photodegradation of Eosin Dye. J. Polym. Sci. Part A: Polym. Chem. 2019, 57 (14), 1538-1549. https://doi.org/10.1002/pola.29416.

(50) Tehfe, M.-A.; Lalevée, J.; Gigmes, D.; Fouassier, J. P. Combination of Transition Metal Carbonyls and Silanes: New Photoinitiating Systems. J. Polym. Sci. A Polym. Chem. 2010, 48 (8), 1830-1837. https://doi.org/10.1002/pola.23956.

(51) Young, T. J.; Monclus, M. A.; Burnett, T. L.; Broughton, W. R.; Ogin, S. L.; Smith, P. A. The Use of the PeakForce ${ }^{\mathrm{TM}}$ Quantitative Nanomechanical Mapping AFM-Based Method for High-Resolution Young's Modulus Measurement of Polymers. Meas. Sci. Technol. 2011, 22 (12), 125703. https://doi.org/10.1088/0957-0233/22/12/125703.

(52) Sader, J. E.; Chon, J. W. M.; Mulvaney, P. Calibration of Rectangular Atomic Force Microscope Cantilevers. Review of Scientific Instruments 1999, 70 (10), 3967-3969. https://doi.org/10.1063/1.1150021.

(53) You, Y.; Gao, S.; Xu, B.; Li, G.; Cao, R. Self-Assembly of Polyoxometalate-Azure A Multilayer Films and Their Photocatalytic Properties for Degradation of Methyl Orange under Visible Light Irradiation. Journal of Colloid and Interface Science 2010, 350 (2), 562-567. https://doi.org/10.1016/j.jcis.2010.07.001.

(54) Hajighasem, A.; Kabiri, K. Cationic Highly Alcohol-Swellable Gels: Synthesis and Characterization. J Polym Res 2013, 20 (8), 218. https://doi.org/10.1007/s10965-0130218-1.

(55) Zhang, X.; Zhang, C.; Guo, H.; Huang, W.; Polenova, T.; Francesconi, L. C.; Akins, D. L. Optical Spectra of a Novel Polyoxometalate Occluded within Modified MCM-41. The Journal of Physical Chemistry B 2005, 109 (41), 19156-19160.

(56) Yamase, T.; Sasaki, R.; Ikawa, T. Photochemical Studies of the Alkylammoniun Molybdates. Part 5. Photolysis in Weak Acid Solutions. J. Chem. Soc., Dalton Trans. 1981, No. 2, 628. https://doi.org/10.1039/dt9810000628. 


\section{TOC Graphic:}

Synthesis of Polyoxometalate/Polymer photo-composites by photopolymerization and characterization for photocatalytic applications

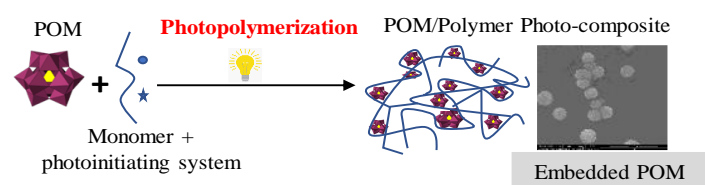

